\title{
The Lateral Hypothalamic Area Controls Paradoxical (REM) Sleep by Means of Descending Projections to Brainstem GABAergic Neurons
}

\author{
Olivier Clément, ${ }^{1,2,3}$ Emilie Sapin, ${ }^{4,5}$ Paul-Antoine Libourel, ${ }^{1,2,3}$ Sébastien Arthaud, ${ }^{1,2,3}$ Frédéric Brischoux, ${ }^{1,2,3}$ \\ Patrice Fort, ${ }^{1,2,3}$ and Pierre-Hervé Luppi ${ }^{1,2,3}$ \\ 'INSERM, U1028; CNRS, UMR5292; Centre de Recherche en Neuroscience de Lyon, Team Physiopathologie des réseaux neuronaux du cycle veille-sommeil, \\ F-69372 Lyon, France, ${ }^{2}$ University of Lyon, F-69000 Lyon, France, ${ }^{3}$ University Claude Bernard Lyon 1, F-69000 Lyon, France, ${ }^{4}$ INSERM U1042, F-38043 \\ Grenoble, France, and 5 Université de Grenoble, F-38043 Grenoble, France
}

It has recently been shown that the ventrolateral part of the periaqueductal gray (VLPAG) and the adjacent dorsal deep mesencephalic nucleus ( $\mathrm{dDpMe}$ ) contain GABAergic neurons gating paradoxical sleep (PS) onset by means of their projection to the glutamatergic PS-on neurons of the sublaterodorsal tegmental nucleus (SLD). To determine the mechanisms responsible for the cessation of activity of these GABAergic PS-off neurons at the onset and during PS, we combined the immunostaining of c-FOS, a marker of neuronal activation, with cholera toxin $b$ subunit (CTb) retrograde tracing from the VLPAG/dDpMe in three groups of rats (control, PS deprived, and PS hypersomniac). We found that the lateral hypothalamic area (LH) is the only brain structure containing a very large number of neurons activated during PS hypersomnia and projecting to the VLPAG/dDpMe. We further demonstrated that $44 \%$ of these neurons express the neuropeptide melanin concentrating hormone $(\mathrm{MCH})$. We then showed that bilateral injections in the LH of two inhibitory compounds, clonidine (an $\alpha-2$ adrenergic agonist) and muscimol (a GABAa agonist) induce an inhibition of PS. Furthermore, after muscimol injections in the LH, the VLPAG/dDpMe contained a large number of activated neurons, mostly GABAergic, and projecting to the SLD. Altogether, our results indicate for the first time that the activation of a population of LH neurons, in part $\mathrm{MCH}$ containing, is necessary for PS to occur. Furthermore, our results strongly suggest that these neurons trigger PS by means of their inhibitory projection to the PS-off GABAergic neurons located in the VLPAG/dDpMe.

\section{Introduction}

Paradoxical sleep (PS), also called rapid eye movement sleep (REM sleep), is characterized by rapid eye movements, cortical activation, and muscle atonia. A number of studies indicate that PS is generated by glutamatergic neurons specifically active during PS (PS-on) located in the pontine sublaterodorsal tegmental nucleus (SLD) (Sakai and Koyama, 1996; Boissard et al., 2002; Lu et al., 2006; Clément et al., 2011; Krenzer et al., 2011). It has further been shown that the activation of these neurons at the onset of PS is due to the removal of a GABAergic input present during waking and slow-wave sleep (SWS). Indeed, blockade of the GABAa receptors in the SLD by the application of GABAa antagonists (bicuculline or gabazine) is sufficient to induce the

\footnotetext{
Received April 18, 2012; revised Sept. 21, 2012; accepted Sept. 25, 2012.

Author contributions: 0.C., P.F., and P.-H.L. designed research; 0.C., E.S., and S.A. performed research; P.-A.L. contributed unpublished reagents/analytic tools; 0 .C. analyzed data; 0.C., F.B., P.F., and P.-H.L. wrote the paper.

This work was supported by INSERM, CNRS, University of Lyon, University Claude Bernard Lyon 1, the French Ministry of Research, and a UCB-Pharma unrestricted research grant. 0.C. received a grant from the French ministry of research.

The authors declare no competing financial interests.

Correspondence should be addressed to Pierre-Hervé Luppi, INSERM, U1028; CNRS, UMR5292, Centre de Recherche en Neuroscience de Lyon, Equipe Physiopathologie des réseaux neuronaux du cycle veille-sommeil, 7 Rue Guillaume Paradin, 69372 Lyon, France. E-mail: luppi@sommeil.univ-lyon1.fr.

DOI:10.1523/JNEUROSCI.1885-12.2012

Copyright $\odot 2012$ the authors $\quad 0270-6474 / 12 / 3216763-12 \$ 15.00 / 0$
}

activation of SLD PS-on neurons and the state of PS (Xi et al., 1999; Boissard et al., 2002). These results highly suggest that a population of GABAergic PS-off neurons tonically inhibits the PS-on glutamatergic neurons of the SLD during waking and SWS. A number of studies indicate that these neurons are localized in the ventrolateral part of the periaqueductal gray (VLPAG) and the adjacent dorsal part of the deep mesencephalic reticular nuclei (dDpMe). Indeed, this region contains most of the GABAergic neurons projecting to the SLD (Boissard et al., 2003) and is the only brainstem region containing a large number of GABAergic neurons activated during $72 \mathrm{~h}$ of PS deprivation ( $\mathrm{Sa}-$ pin et al., 2009). In addition, inactivation of the VLPAG/dDpMe region by muscimol (a GABAa agonist) application, or its neurochemical lesion, induces strong increases in PS quantities (Sastre et al., 1996; Crochet et al., 2006; Lu et al., 2006; Vanini et al., 2007; Kaur et al., 2009; Sapin et al., 2009).

It has then been shown that, in PS hypersomniac rats, the SLD contains c-FOS expressing and GABAergic neurons projecting to the VLPAG/dDpMe (Lu et al., 2006). From these and our results, the authors hypothesized that a mutual inhibitory interaction between GABAergic SLD PS-on and GABAergic VLPAG/dDpMe PS-off neurons constitutes a brainstem flip-flop switch controlling PS onset and maintenance (Lu et al., 2006). However, we did not confirm the presence of c-FOS/gad67 double-labeled neurons in the SLD in PS hypersomniac animals (Sapin et al., 2009). 
Instead, we reported a large number of c-FOS/gad67 doublelabeled neurons in other afferents known to project to the VLPAG/dDpMe (Behbehani, 1995; Kaur et al., 2009; Hsieh et al., 2011), such as the lateral hypothalamic area (LH), the other PAG subdivisions, and the dorsal paragigantocellular reticular nucleus (DPGi) (Sapin et al., 2009, 2010).

Therefore, to determine whether the latter structures or the SLD control the activity of the PS-off GABAergic neurons of the VLPAG/dDpMe, we decided to map in the entire brain neurons activated during PS hypersomnia and projecting to the VLPAG/ dDpMe. We found that the LH is the only brain structure containing a very large number of neurons activated during PS hypersomnia projecting to the VLPAG/dDpMe. We then determined the effect on PS of pharmacological inactivation of $\mathrm{LH}$ neurons.

\section{Materials and Methods}

All experiments were conducted in accordance to the French and European Community guidelines for the use of research animals and approved by the Institutional Animal Care and Use Committee of the University of Lyon 1 (Protocols BH 2006-07 and BH 2006-09). Sprague Dawley male rats were housed individually in recording barrels under a constant $12 \mathrm{~h}$ light/dark cycle (light on at 08:00 A.M.). Room temperature was maintained at $21 \pm 1^{\circ} \mathrm{C}$, and food and water were available ad libitum throughout the experiments.

\section{Surgery}

Retrograde tracing. Rats (290-300 g, Charles River) were anesthetized with a Ketamine/Xylazine mix $\left(100 \mathrm{mg} \cdot \mathrm{kg}^{-1}\right.$ and $10 \mathrm{mg} \cdot \mathrm{kg}^{-1}$ respectively, i.p.) and mounted in a stereotaxic frame (David Kopf Instruments). Following incision of the scalp, a hole was drilled in the skull and a borosilicate glass micropipette ( $3-5 \mu \mathrm{m}$ external tip diameter) backfilled with a low-salt CTb solution ( $0.5 \%$ in $0.1 \mathrm{M} \mathrm{PB}, \mathrm{pH}$ 6; List Biological Laboratories) (Luppi et al., 1988) was slowly lowered by means of a hydraulic micropositioner (David Kopf Instruments) into the VLPAG/ dDpMe $(n=24)$ or the SLD $(n=2)$ according to their stereotaxic coordinates (VLPAG/dDpMe: anterior (A)-posterior (P), -7; medial (M)-lateral (L), +0.8; dorsal (D)-ventral (V), -5.2; SLD AP, -9.6; ML, +1.2 ; DV,-5.8 ; distances in $\mathrm{mm}$ from bregma, except for $\mathrm{DV}$ that is from the brain surface). The micropipette was left in place for $5 \mathrm{~min}$ before the tracer was iontophoretically ejected. For this purpose, the micropipette was connected by a silver wire immersed in the CTb solution to a current generator (CS4, Transkinetics) that delivered a pulsed positive current ( $7 \mathrm{~s}$ on/7 s off) for $15 \mathrm{~min}$ (Luppi et al., 1988). At the end of the ejection, the pipette was left in place for at least $10 \mathrm{~min}$ to avoid leakage of the tracer along the pipette track.

Cannula implantation. Eight rats (290-310 g), including the two with a CTb injection in the SLD, were bilaterally implanted with a 26 gauge guide cannula $2.6 \mathrm{~mm}$ above the $\mathrm{LH}(\mathrm{AP},-3.3$; $\mathrm{ML}, \pm 1.8$; DV,-8.5$)$. Due to space constraint, guide cannulas were implanted with a $10^{\circ}$ lateral angle. They were then cemented to the skull using acrylic cement (Superbond, Sun Medical) and dental cement (Paladur, Heraeus Kulzer).

EEG/EMG implantation. All the rats were implanted for electroencephalographic (EEG) and electromyographic (EMG) recordings. As previously described (Verret et al., 2005, 2006; Sapin et al., 2009), four stainless-steel screws (Anthogyr) were inserted over the frontal (AP, +3; $\mathrm{ML},+1)$, parietal (AP, -4 ; ML, +3), occipital (AP, -8 ; ML, +3), and cerebellar (AP, $-12 ; \mathrm{ML},+2)$ cortices. Two gold-coated electrodes were also inserted into the neck muscles to record EMG activity. All EMG and EEG electrodes were then fixed to the skull using acrylic cement (Superbond) and connected to a miniature plug (Plastics One) that was cemented using dental cement (Paladur).

\section{Paradoxical sleep deprivation and recovery}

After the surgery, rats $(n=24)$ were allowed to recover for $5 \mathrm{~d}$, during which time they were weighed daily, before being habituated to the recording conditions for at least $4 \mathrm{~d}$ and then recorded during a $2 \mathrm{~d}$ baseline. Then, PS deprivation was performed using the well characterized flowerpot method (Maloney et al., 1999, 2000, 2002; Verret et al., 2003, 2005, 2006; Léger et al., 2009; Sapin et al., 2010; Clément et al., 2011). The rats were separated in three groups of four. Rats of the control group (PSC) remained on a bed of woodchips throughout the experiment. PS-deprived rats (PSD) were placed at 11:00 A.M. for $75 \mathrm{~h}$ in a barrel containing a small platform $(6.5 \mathrm{~cm}$ in diameter) surrounded by water. PS hypersomniac rats (PSR for PS-recovering) were submitted to the same deprivation as the PSD animals for 72 h. At 11:00 A.M. on the last day of the experiment, PSR rats were removed from the deprivation barrel and put in a new barrel with a dry bed of woodchips to recover from PS-deprivation. PSR rats were killed exactly $150 \mathrm{~min}$ after the first PS episode, which generally occurs after $30 \mathrm{~min}$ of exploration and grooming. PSC and PSD rats were killed at 2:00 P.M. Each day during PS-deprivation, PSD and PSR animals were put in a clean barrel for $\sim 30-45$ min while their deprivation barrels were cleaned.

\section{Pharmacology}

Animals $(n=8)$ were allowed to recover for $5 \mathrm{~d}$ after the surgery, during which time they were weighed daily. They were then habituated to the recording conditions and handled daily for at least 15 min during 1 week to minimize nonspecific stress. Muscimol ( $0.3 \mu \mathrm{l}$; GABAa receptor agonist, $1 \mu \mathrm{g} \cdot \mu \mathrm{l}^{-1}$ in $\mathrm{NaCl} 0.9 \%$; Sigma-Aldrich), clonidine hydrochloride $\left(\alpha\right.$-2 adrenoreceptor agonist, $0.53 \mu \mathrm{g} \cdot \mu \mathrm{l}^{-1}$ in $\mathrm{NaCl} 0.9 \%$; Tocris Bioscience), or $\mathrm{NaCl}(0.9 \%)$ were injected in each hemisphere at the rate of $0.1 \mu \mathrm{l} \cdot \min ^{-1}$ using a Hamilton syringe (Hamilton) connected to the cannula with the appropriate polyethylene tubing (Plastics One) and inserted into a micro-pump (New Era Pump System). The 33 gauge cannulas (Plastics One) protruded out $2.6 \mathrm{~mm}$ from the guide cannula.

All injections started at 9:20 A.M. Cannulas were lowered down the brain and left in place $5 \mathrm{~min}$ before and after the injection. Animals were then put back in their barrel and vigilance states were recorded for $16 \mathrm{~h}$. All drugs were stored at their final concentration at $-20^{\circ} \mathrm{C}$ and one new batch was used for each injection. Each rat received three injections ( $\mathrm{NaCl}$, clonidine hydrochloride, and muscimol) spaced by at least $3 \mathrm{~d}$ and the sequence of drug injections was randomized. Finally, each rat received a final injection of either muscimol $(n=4)$ or $\mathrm{NaCl}(n=4)$ and was perfused $3 \mathrm{~h}$ after the end of injection.

\section{Polygraphic recordings}

Rats were connected to a cable attached to a rotating connector (Plastics One) to allow free movements of the animal within its cage. EEG and EMG signals were amplified (MCP+, Alpha-Omega Engineering) and collected on a computer via a CED interface using Spike2 software (Cambridge Electronic Design). For all animals, the same amplification was used and each animal remained in the same recording box during the entire experiment. Sampling frequency for polygraphic recordings was $520.8 \mathrm{~Hz}$

\section{Perfusion, fixation, and sectioning}

Under deep pentobarbital anesthesia (Ceva santé animale, $150 \mathrm{mg} \cdot \mathrm{kg}^{-1}$, i.p.), rats were transcardially perfused with Ringer's lactate solution containing $0.1 \%$ heparin, followed by $500 \mathrm{ml}$ of a cold fixative solution composed of $4 \%$ paraformaldehyde in $0.1 \mathrm{~m}$ phosphate buffer $(\mathrm{PB}, \mathrm{pH}$ 7.4). The brains were removed, stored overnight at $4^{\circ} \mathrm{C}$ in the fixative solution, and then left for $3 \mathrm{~d}$ in $30 \%$ sucrose in $0.1 \mathrm{M} \mathrm{PB}$. Brains were then rapidly frozen in methyl-butane cooled with dry ice and 30- $\mu \mathrm{m}$ thick coronal sections were cut on a cryostat (Microm). Free-floating sections were collected and stored at $-20^{\circ} \mathrm{C}$ in a RNase free cryoprotectant solution (Sapin et al., 2009, 2010; Clément et al., 2011).

\section{Immunohistochemistry}

As previously described (Boissard et al., 2002), brain sections were successively incubated in (1) a rabbit antiserum against c-FOS (1:10,000; Merck) in PBST-Az (PBS containing $0.3 \%$ of Triton X-100 and $0.1 \%$ of Natriumazide) for $3 \mathrm{~d}$ at $4^{\circ} \mathrm{C}$; (2) a biotinylated goat anti-rabbit IgG solution (1:1000; Vector Laboratories); and (3) an ABC-HRP solution (1:1000; Elite kit, Vector Laboratories) both for $90 \mathrm{~min}$ at room temperature. Finally, the staining was revealed in a $0.05 \mathrm{~m}$ Tris- $\mathrm{HCl}$ buffer, $\mathrm{pH}$ 7.6, containing $0.025 \%$ 3,3'-diaminobenzidine-4 HCl (DAB; SigmaAldrich), $0.003 \% \mathrm{H}_{2} \mathrm{O}_{2}$, and $0.6 \%$ nickel ammonium sulfate. Three 


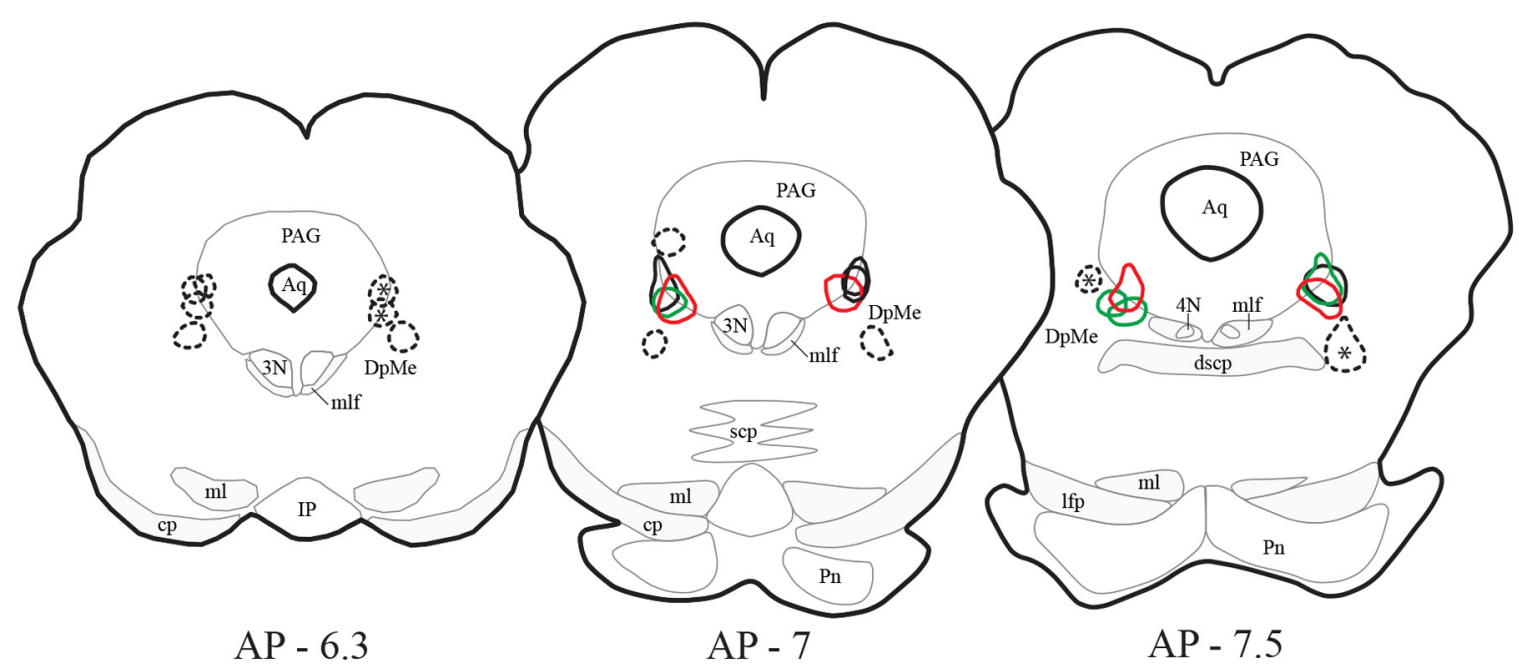

Figure 1. Localization of the CTb injection sites. The cores of the 12 CTb injection sites located in the VLPAG/dDpMe are delineated by red, green, and black lines for PS hypersomniac, PS deprived, and control animals, respectively. The cores of the injection sites were defined by a dense full labeling of the tissue in contrast to the halo surrounding them in which CTb labeling was observed in fibers and cell bodies. These animals were used for the analysis of $\mathrm{CTb} / \mathrm{c}-$ Fos double-labeling across the entire brain. Black dashed lines delineate the $12 \mathrm{CTb}$ control injections sites localized in the structures surrounding the VLPAG/dDpMe. The sites labeled with an asterisk correspond to the four control injections obtained in PS hypersomniac animals and for which CTb + and $\mathrm{CTb} / \mathrm{c}-\mathrm{FOS}+$ neurons were counted in the entire brain.

washes of 10 min were performed between each step. The c-FOS immunostained sections were then incubated the following day in a goat polyclonal antibody against hypocretin (HCRT; 1:5000; Santa Cruz Biotechnology), a rabbit antiserum against the neuropeptide melanin concentrating hormone ( $\mathrm{MCH}, 1: 20,000$; Phoenix Pharmaceutical), or a goat antiserum against CTb (1:40,000; List Biological Laboratories) in PBST-Az over $3 \mathrm{~d}$ at $4^{\circ} \mathrm{C}$. Amplification steps were similar to those described above, except that the last step was performed in DAB solution without nickel ammonium sulfate. Finally, the sections were mounted on glass slides, dried, and coverslipped with DePex.

For the triple labeling of c-FOS, $\mathrm{MCH}$, and $\mathrm{CTb}$, the first step for c-FOS was performed as described above. Then c-FOS stained sections were incubated for (1) $3 \mathrm{~d}$ at $4^{\circ} \mathrm{C}$ in PBST-Az containing the $\mathrm{MCH}$ rabbit antiserum (1:5000) and the CTb goat antiserum (1:10,000) and (2) $2 \mathrm{~h}$ in PBST containing the fluorescent secondary antibodies (Alexa Fluor 488 donkey anti-rabbit IgG, 1/500; Alexa Fluor 546 donkey anti-goat IgG, 1/500; Invitrogen). Finally, sections were rinsed in PBST, mounted on glass slides, and coverslipped with Mowiol 4-88 (Merck). The analysis of immunostained neurons was performed immediately to prevent fading of fluorescence.

\section{c-FOS immunohistochemistry combined with gad67 or neurotensin $m R N A$ in situ hybridization}

The antisense and sense digoxigenin-labeled probes against the $67 \mathrm{kDa}$ isoform of glutamic acid decarboxylase ( gad67) and neurotensin mRNA were synthesized from a recombinant linearized plasmid containing the gad67 or neurotensin cDNA using a nonradioactive RNA labeling kit (Roche Diagnostic). As described previously (Sapin et al., 2009, 2010; Clément et al., 2011), the brain sections were successively incubated overnight with a rabbit antiserum against c-FOS (1:4000; Merck), 90 min in a biotinylated goat anti-rabbit IgG solution (1:1000; Vector Laboratories), and $90 \mathrm{~min}$ in an ABC-HRP solution (1:1000; Elite kit, Vector Laboratories). Then, the sections were revealed for $\sim 15 \mathrm{~min}$ in a $0.05 \mathrm{M}$ Tris- $\mathrm{HCl}$ buffer, $\mathrm{pH}$ 7.6, containing $0.025 \%$ DAB (Sigma-Aldrich) and $0.003 \% \mathrm{H}_{2} \mathrm{O}_{2}$. All buffers contained $0.2 \%$ of RNase inhibitor (solution Protect RNA RNase inhibitor, Sigma-Aldrich). They were then rinsed in PBST containing $10 \mathrm{~mm}$ dithio-threitol (DTT, Sigma-Aldrich) and a standard saline citrate solution (SSC $2 \times$ ). Sections were then placed overnight at $65^{\circ} \mathrm{C}$ in the hybridization buffer containing $0.5 \mu \mathrm{g} \cdot \mathrm{ml}^{-1}$ of the digoxigenin-labeled probe. Sections were washed in SSC $1 \times, 50 \%$ formamide, $0.1 \%$ Tween 20, and treated with RNase A (USB Corporation). Sections were then incubated with an anti-digoxigenin antibody conjugated to alkaline phosphatase (1:2000, Roche Diagnostic). Staining was revealed using nitroblue tetrazolium and 5-bromo-4-chloro-3indolyl-phosphate (Roche Diagnostic). Finally, the sections were mounted on slides, dried, and coverslipped with Vectamount (Vector Laboratories). Controls in the absence of primary antibodies (anti-c-FOS and anti-digoxigenin) or with the sense probe were run to ensure for the specificity of the labeling.

\section{Quantification of the sleep-wake cycle}

For the PS-deprivation/recovery experiments, the polygraphic recordings were analyzed in each animal for the last $150 \mathrm{~min}$ before death. For the pharmacological experiments, the analysis was performed for the $16 \mathrm{~h}$ following the injections. Vigilance states were manually scored by $5 \mathrm{~s}$ epochs using a homemade script developed using Spike2 software (Cambridge Electronic Design). State classification was done by a visual check of polygraphic signals and the help of a sliding window showing the EEG power spectrum analyzed during the same $5 \mathrm{~s}$ epoch by fast Fourier transform. Waking was characterized by a desynchronized (activated) low-amplitude EEG accompanied by a sustained EMG activity; SWS was distinguished by high-voltage slow waves $(1.5-4.0 \mathrm{~Hz})$ and spindles $(10-14 \mathrm{~Hz})$ and the disappearance of phasic muscle activity. The occurrence of muscle atonia with a regular and pronounced theta rhythm (4-9 $\mathrm{Hz}$ ) characterized PS. We then calculated the mean quantities, percentages, number, and duration of episodes for each vigilance state. For pharmacological experiments, SWS and PS latencies were also calculated. They were defined as the time between the end of the injection session and the first SWS, or PS, episode, respectively.

\section{Quantitative analysis of labeled neurons}

$C T b / c-F O S$ analysis after PS deprivation and recovery. We exhaustively mapped c-FOS singly (c-FOS + ), CTb singly $(\mathrm{CTb}+)$, and $\mathrm{CTb} / \mathrm{c}-\mathrm{FOS}$ double-labeled $(\mathrm{CTb} / \mathrm{c}-\mathrm{FOS}+)$ neurons from $\mathrm{AP}+0.4$ to $\mathrm{AP}-12.8$ in four animals per condition (PSC, PSD, PSR) with an injection site located in the VLPAG/dDPMe and in four control PSR animals with CTb injections in the structures surrounding the VLPAG/dDPMe (Fig. 1). Labeled neurons localized in the halo immediately surrounding the injections sites were not counted. Bilateral drawings of double-labeled sections taken at $600 \mu \mathrm{m}$ intervals were made with an Axioskop microscope (Zeiss) equipped with a motorized $\mathrm{X}-\mathrm{Y}$-sensitive stage and a video camera connected to a computerized image analysis system (Mercator; ExploraNova). The number of c-FOS,$+ \mathrm{CTb}+$, and $\mathrm{CTb} / \mathrm{c}-\mathrm{FOS}+$ neurons per structure was automatically counted and exported using Mercator (ExploraNova). When a structure was present on several sections, the neurons counted on all sections were summed. The atlas of Paxinos and 

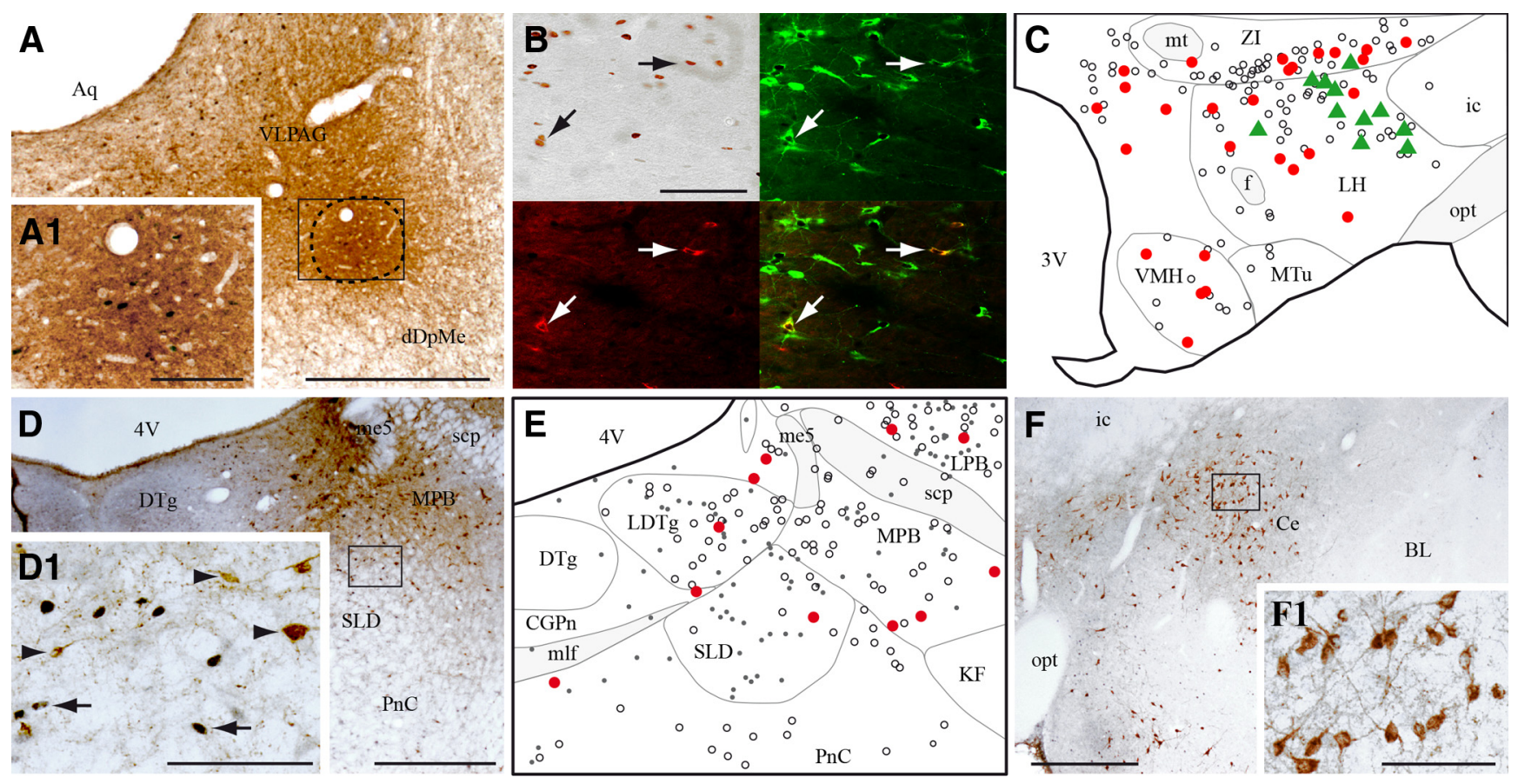

Figure 2. VLPAG/dDpMe afferents expressing c-FOS during PS-hypersomnia. $\boldsymbol{A}$, Illustration of a CTb injection site located at the border of the VLPAG and dDpMe in a PS-deprived rat. The enlargement in $\boldsymbol{A} \mathbf{1}$ shows the numerous (-FOS + neurons within the core of the injection site (delineated by a line) indicating that the neurons specifically active during PS deprivation were effectively targeted. B, Composite photomicrograph illustrating a triple labeling for c-FOS (DAB staining, top left), CTb (in red, bottom left), and MCH (in green, top left) in a PSR animal. An overlay photomicrograph is shown at the bottom right. Arrows point out triple labeled neurons. C, Schematic distribution of (Tb/c-FOS/MCH + (green triangles), (Tb/c-FOS + (red dots), and singly CTb+ (open circles) neurons within the tuberal hypothalamus (AP, $-2.6 \mathrm{~mm}$ ) in a PSR animal. D, Photomicrograph showing that the SLD contains only singly CTb + (brown cytoplasm) and singly c-FOS + (black nuclear staining) neurons in PSR animals. The box in D is enlarged in D1. Arrows and arrowheads point to c $-F O S+$ and $C T b+$ singly labeled neurons, respectively. E, Schematic illustration of singly (Tb + (open circles), singly c-FOS + (black dots), and CTb/c-FOS + (red dots) neurons in the SLD and surrounding structures (AP, $-9.2 \mathrm{~mm}$ ) in a PSR animal. $F$, Photomicrograph showing in a PSR animal the large number of singly CTb + cells (brown cytoplasmic labeling) in the Ce after a CTb injection in the VLPAG/dDpMe. The square area is enlarged in $\boldsymbol{F 1}$. Scale bars: $\boldsymbol{A}, \boldsymbol{D}, \boldsymbol{F}, 500 \mu \mathrm{m}$; $A 1, D 1, F 1,100 \mu \mathrm{m} ; \boldsymbol{B}, 200 \mu \mathrm{m} .3 \mathrm{~V}$, Third ventricle; $4 \mathrm{~N}$, trochlear nucleus; 4V, fourth ventricle; Aq, aqueduct; BL, basolateral amygdaloid nucleus; (GPn, central gray of the pons; $f$, fornix; ic, internal capsule; me5, mesencephalic trigeminal tract; mlf, medial longitudinal fasciculus; MPB, medial parabrachial nucleus; mt, mammillothalamic tract; MTu, medial tuberal nucleus; opt, optic tract; $V M M H$, ventromedial hypothalamic nucleus.

Watson (Paxinos and Watson, 1998) was used as a reference for all structures except the SLD that was named and delineated according to Swanson (1998).

$\mathrm{CTb} / \mathrm{c}-\mathrm{FOS} / \mathrm{MCH}$ triple labeling. For this part of the experiment, one side (ipsilateral to the CTb injection) of four sections spaced at $360 \mu \mathrm{m}$ taken at the level the LH was analyzed. The number of $\mathrm{CTb} / \mathrm{c}-\mathrm{FOS}+$ and $\mathrm{CTb} / \mathrm{c}-\mathrm{FOS} / \mathrm{MCH}+$ neurons were then counted and summed for these four sections. The analysis was only performed in the four animals of the PSR group as MCH neurons do not express c-FOS in control and PSdeprived conditions (Verret et al., 2003).

c-FOS/neurotensin double labeling in the LH. In four PSR animals, the number of c-FOS + , neurotensin + , and c-FOS/neurotensin + neurons was counted in the LH on two sections spaced by $200 \mu \mathrm{m}$.

Histological analysis following muscimol injection in the LH. For all animals perfused after muscimol or $\mathrm{NaCl}$ injections $(n=4$ in each group), the number of c-FOS/HCRT+, c-FOS/MCH+, and c-FOS/ gad67+ neurons was counted on one section containing the LH (AP, -2.5) for HCRT and MCH, or the VLPAG/dDPMe (AP, -7.4) for gad67. Since the distribution of c-FOS labeling was similar on both sides of the brain, only one side was counted.

\section{Statistical analysis}

Because of the small number of animals used in each experiment, nonparametric statistical tests were used. For the comparison of vigilance states and the number of labeled neurons across PSC, PSD, and PSR conditions, Kruskal-Wallis tests were used, followed by a after hoc PLSD Mann-Whitney $U$ test to identify pairwise differences. For the pharmacological results, statistical differences in state quantities, latency, duration, and number of episodes between $\mathrm{NaCl}$ and muscimol or clonidine were determined with a Wilcoxon signed-rank test. Statistical differences in the number of HCRT/c-FOS,$+ \mathrm{MCH} / \mathrm{c}-\mathrm{FOS}+$, or $\mathrm{gad} 67 / \mathrm{c}-\mathrm{FOS}+$ neurons were determined with a Mann-Whitney $U$ test. All statistics were performed using StatView software and a significant effect was considered when $p<0.05$.

\section{Results}

\section{Sleep quantities}

We used the well characterized and reproducible inverted flowerpot method to modulate PS quantities in rats (Maloney et al., 1999, 2000, 2002; Verret et al., 2003, 2005, 2006; Léger et al., 2009; Sapin et al., 2009, 2010; Clément et al., 2011). During the last $150 \mathrm{~min}$ before death, PS was almost eliminated in PS-deprived rats (PSD rats, $n=$ $4 ; 0.2 \pm 0.2 \%$ ) compared with control animals (PSC rats, $n=4$; $12.2 \pm 2.1 \%$, Mann-Whitney $U$ test, $Z=-2.309, p=0.02)$. The animals recovering from deprivation (PSR rats, $n=4$ ) showed a strong and significant increase in PS quantities (47.3 $\pm 4.8 \%)$ compared with PSC (Mann-Whitney $U$ test, $Z=-2.309, p=$ 0.02 ) and PSD (Mann-Whitney $U$ test, $Z=-2.309, p=0.02$ ) animals. The PSD $(32.6 \pm 4.9 \%$, Mann-Whitney $U$ test, $Z=$ $-2.021, p=0.04)$ and PSR $(34.0 \pm 2.0 \%$, Mann-Whitney $U$ test, $Z=-2.309, p=0.02$ ) rats also showed a significant reduction in SWS compared with control animals $(53.2 \pm 4.2 \%)$ at the benefit of waking and PS, respectively. The increase in PS quantities in PSR rats compared with control animals was due to an increase in the duration of PS episodes $(3.4 \pm 0.4 \mathrm{~min}$ vs $1.5 \pm 0.2 \mathrm{~min}$, Mann-Whitney $U$ test, $Z=-2.309, p=0.02$ ). The number of PS episodes tended to increase in the PSR condition but was not 


\begin{tabular}{|c|c|c|c|c|c|c|c|c|c|}
\hline & \multirow[b]{3}{*}{$n$} & \multirow{2}{*}{\multicolumn{2}{|c|}{$\mathrm{CTb}+$}} & \multicolumn{6}{|l|}{$\mathrm{CTb} / \mathrm{c}-\mathrm{FOS}+$} \\
\hline & & & & \multicolumn{2}{|l|}{ PSR } & \multicolumn{2}{|l|}{ PSD } & \multicolumn{2}{|l|}{ PSC } \\
\hline & & Ipsi & Contra & Ipsi & Contra & Ipsi & Contra & Ipsi & Contra \\
\hline \multicolumn{10}{|c|}{ Basal forebrain } \\
\hline BST & 2 & $117.6 \pm 8.8$ & $18.5 \pm 2.2$ & $5.3 \pm 0.9$ & $1.8 \pm 1.1$ & $2.3 \pm 0.5$ & $0.5 \pm 0.5$ & $0.8 \pm 0.5$ & $0.0 \pm 0.0$ \\
\hline $\mathrm{MnPO}$ & 1 & $6.3 \pm 1.1$ & & $1.8 \pm 0.6$ & & $0.0 \pm 0.0$ & & $0.8 \pm 0.3$ & \\
\hline MPO & 2 & $20.8 \pm 0.5$ & $7.3 \pm 0.1$ & $2.5 \pm 1.5$ & $1.3 \pm 0.6$ & $1.0 \pm 0.7$ & $0.3 \pm 0.3$ & $0.8 \pm 0.5$ & $1.0 \pm 0.6$ \\
\hline LPO & 2 & $28.3 \pm 3.5$ & $5.3 \pm 0.7$ & $2.0 \pm 0.7$ & $0.3 \pm 0.3$ & $1.8 \pm 0.8$ & $0.5 \pm 0.5$ & $0.3 \pm 0.3$ & $0.0 \pm 0.0$ \\
\hline \multicolumn{10}{|l|}{ Thalamus } \\
\hline APT & 2 & $66.8 \pm 1.3$ & $31.8 \pm 1.1$ & $10.5 \pm 3.8$ & $8.8 \pm 2.6$ & $4.3 \pm 2.1$ & $3.8 \pm 1.9$ & $2.8 \pm 0.5$ & $4.8 \pm 1.3$ \\
\hline LG & 3 & $14.5 \pm 0.9$ & $2.2 \pm 0.4$ & $1.5 \pm 0.3$ & $0.0 \pm 0.0$ & $0.8 \pm 0.5$ & $1.3 \pm 0.9$ & $0.5 \pm 0.3$ & $0.0 \pm 0.0$ \\
\hline \multicolumn{10}{|l|}{ Amygdala } \\
\hline Ce & 3 & $117.9 \pm 13.6$ & $9.2 \pm 2.1$ & $4.0 \pm 1.0$ & $0.5 \pm 0.3$ & $1.3 \pm 0.9$ & $0.3 \pm 0.3$ & $0.5 \pm 0.5$ & $0.0 \pm 0.0$ \\
\hline \multicolumn{10}{|c|}{ Hypothalamus } \\
\hline VMH & 4 & $97.6 \pm 8.5$ & $29.8 \pm 3.0$ & $7.8 \pm 2.1$ & $2.8 \pm 1.1$ & $2.3 \pm 1.9$ & $0.3 \pm 0.3$ & $5.3 \pm 1.7$ & $1.0 \pm 0.4$ \\
\hline PMD & 1 & $14.3 \pm 0.7$ & $0.4 \pm 0.0$ & $0.8 \pm 0.8$ & $0.0 \pm 0.0$ & $3.3 \pm 2.9$ & $0.0 \pm 0.0$ & $0.0 \pm 0.0$ & $0.0 \pm 0.0$ \\
\hline AHC & 1 & $12.8 \pm 1.1$ & $5.3 \pm 0.3$ & $1.3 \pm 0.5$ & $0.8 \pm 0.5$ & $0.3 \pm 0.3$ & $0.3 \pm 0.3$ & $0.0 \pm 0.0$ & $0.5 \pm 0.3$ \\
\hline AHP & 1 & $6.1 \pm 0.9$ & $2.5 \pm 0.3$ & $1.3 \pm 0.6$ & $1.0 \pm 0.6$ & $0.3 \pm 0.3$ & $0.0 \pm 0.0$ & $0.3 \pm 0.3$ & $0.0 \pm 0.0$ \\
\hline $\mathrm{DA}$ & 1 & $25.6 \pm 0.5$ & $7.6 \pm 0.5$ & $4.8 \pm 1.8$ & $1.0 \pm 0.7$ & $2.8 \pm 0.9$ & $1.3 \pm 0.8$ & $2.3 \pm 0.5$ & $0.0 \pm 0.0$ \\
\hline DM & 3 & $9.2 \pm 0.5$ & $3.9 \pm 0.2$ & $1.5 \pm 0.6$ & $0.3 \pm 0.3$ & $0.5 \pm 0.5$ & $0.3 \pm 0.3$ & $1.0 \pm 0.6$ & $0.3 \pm 0.3$ \\
\hline $\mathrm{Pa}$ & 2 & $5.9 \pm 1.0$ & $1.4 \pm 0.2$ & $1.5 \pm 0.9$ & $0.3 \pm 0.3$ & $0.3 \pm 0.3$ & $0.3 \pm 0.3$ & $0.3 \pm 0.3$ & $0.0 \pm 0.0$ \\
\hline $\mathrm{PH}$ & 3 & $97.8 \pm 8.6$ & $27.3 \pm 1.7$ & $12.5 \pm 2.8^{*}$ & $3.5 \pm 1.0$ & $5.0 \pm 0.7$ & $1.3 \pm 0.6$ & $3.3 \pm 0.3$ & $0.5 \pm 0.3$ \\
\hline LH & 7 & $448.3 \pm 23.0$ & $111.8 \pm 8.1$ & $55.8 \pm 4.0^{*, \#}$ & $21.0 \pm 3.7^{*, \#}$ & $26.3 \pm 5.9$ & $5.3 \pm 1.1$ & $10.0 \pm 1.4$ & $4.3 \pm 1.7$ \\
\hline ZI & 6 & $435.7 \pm 25.4$ & $62.7 \pm 0.6$ & $27.5 \pm 5.8^{*, \#}$ & $13.0 \pm 2.0^{*, \#}$ & $9.5 \pm 2.0$ & $2.0 \pm 0.4$ & $9.5 \pm 0.6$ & $1.0 \pm 0.6$ \\
\hline \multicolumn{10}{|c|}{ Mesencephalon } \\
\hline IC & 2 & $30.2 \pm 4.2$ & $10.5 \pm 1.0$ & $0.5 \pm 0.5$ & $0.8 \pm 0.5$ & $1.8 \pm 1.2$ & $0.8 \pm 0.5$ & $0.3 \pm 0.3$ & $0.0 \pm 0.0$ \\
\hline SC & 4 & $533.8 \pm 31.4$ & $102.8 \pm 5.6$ & $18.0 \pm 5.7$ & $5.0 \pm 1.4$ & $11.0 \pm 5.1$ & $2.3 \pm 1.0$ & $4.3 \pm 1.4$ & $0.8 \pm 0.8$ \\
\hline DpMe & 7 & $662.8 \pm 12.2$ & $173.8 \pm 5.1$ & $14.3 \pm 5.1^{*}$ & $6.3 \pm 3.3$ & $4.8 \pm 1.9$ & $2.3 \pm 0.8$ & $0.8 \pm 0.8$ & $1.0 \pm 0.4$ \\
\hline RRF & 6 & $68.3 \pm 6.1$ & $17.0 \pm 1.9$ & $1.5 \pm 0.6$ & $0.0 \pm 0.0$ & $1.5 \pm 0.9$ & $0.3 \pm 0.3$ & $0.0 \pm 0.0$ & $0.0 \pm 0.0$ \\
\hline SNC & 2 & $49.3 \pm 2.1$ & $9.8 \pm 0.4$ & $1.3 \pm 0.6$ & $0.0 \pm 0.0$ & $1.3 \pm 1.3$ & $0.0 \pm 0.0$ & $0.0 \pm 0.0$ & $0.0 \pm 0.0$ \\
\hline SNR & 4 & $52.5 \pm 4.2$ & $6.0 \pm 0.4$ & $1.8 \pm 0.6$ & $0.0 \pm 0.0$ & $0.8 \pm 0.5$ & $0.0 \pm 0.0$ & $0.5 \pm 0.3$ & $0.0 \pm 0.0$ \\
\hline \multicolumn{10}{|c|}{ Periaqueductal gray } \\
\hline RMPAG & 2 & $168.8 \pm 2.0$ & $69.2 \pm 1.0$ & $20.0 \pm 3.0^{*, \#}$ & $9.8 \pm 1.4^{*, \#}$ & $8.0 \pm 1.7$ & $3.5 \pm 1.3$ & $4.3 \pm 0.8$ & $2.0 \pm 0.4$ \\
\hline DMPAG & 6 & $175.7 \pm 8.6$ & & $26.0 \pm 2.6^{*, \#}$ & & $2.3 \pm 0.9^{*}$ & & $4.8 \pm 0.5$ & \\
\hline DLPAG & 5 & $110.8 \pm 5.4$ & $28.7 \pm 1.6$ & $13.8 \pm 2.3^{*, \#}$ & $4.8 \pm 0.9^{*, \#}$ & $2.0 \pm 0.9$ & $0.0 \pm 0.0$ & $0.5 \pm 0.3$ & $0.3 \pm 0.3$ \\
\hline LPAG & 6 & $295.8 \pm 5.8$ & $77.5 \pm 3.1$ & $21.8 \pm 2.5^{*}$ & $10.3 \pm 2.4^{*}$ & $19.3 \pm 2.5^{*}$ & $4.0 \pm 1.1$ & $5.0 \pm 1.5$ & $1.8 \pm 1.0$ \\
\hline VLPAG & 5 & $332.0 \pm 5.9$ & $138.0 \pm 0.9$ & $22.0 \pm 3.7^{*, \#}$ & $9.8 \pm 1.9^{*, \#}$ & $9.5 \pm 1.2^{*}$ & $4.3 \pm 1.1$ & $4.5 \pm 1.0$ & $3.3 \pm 0.9$ \\
\hline DR & 3 & $42.2 \pm 5.6$ & & $2.3 \pm 0.9$ & & $0.5 \pm 0.3$ & & $0.5 \pm 0.3$ & \\
\hline \multicolumn{10}{|l|}{ Pons } \\
\hline LDTg & 2 & $33.8 \pm 2.1$ & $11.5 \pm 0.9$ & $1.8 \pm 0.6$ & $1.5 \pm 0.6$ & $1.0 \pm 0.7$ & $0.3 \pm 0.3$ & $0.8 \pm 0.5$ & $0.0 \pm 0.0$ \\
\hline CGPn & 3 & $42.6 \pm 4.3$ & $15.4 \pm 1.3$ & $4.0 \pm 1.1$ & $1.3 \pm 0.5$ & $2.8 \pm 0.3$ & $0.3 \pm 0.3$ & $1.8 \pm 0.5$ & $0.0 \pm 0.0$ \\
\hline $\mathrm{CnF}$ & 2 & $71.6 \pm 4.5$ & $24.8 \pm 0.3$ & $1.5 \pm 0.3$ & $1.5 \pm 1.0$ & $1.0 \pm 1.0$ & $0.3 \pm 0.3$ & $1.8 \pm 0.5$ & $0.5 \pm 0.5$ \\
\hline LC & 2 & $0.9 \pm 0.2$ & $0.7 \pm 0.1$ & $0.0 \pm 0.0$ & $0.0 \pm 0.0$ & $0.0 \pm 0.0$ & $0.0 \pm 0.0$ & $0.0 \pm 0.0$ & $0.0 \pm 0.0$ \\
\hline $\mathrm{KF}$ & 2 & $29.8 \pm 2.6$ & $11.6 \pm 0.5$ & $0.5 \pm 0.5$ & $0.3 \pm 0.3$ & $2.5 \pm 1.5$ & $2.3 \pm 1.9$ & $0.3 \pm 0.3$ & $0.5 \pm 0.3$ \\
\hline LPB & 3 & $99.8 \pm 2.7$ & $34.8 \pm 3.0$ & $11.5 \pm 2.2$ & $5.5 \pm 3.0$ & $6.8 \pm 1.3$ & $2.3 \pm 0.9$ & $5.8 \pm 0.5$ & $1.0 \pm 0.6$ \\
\hline MPB & 3 & $59.4 \pm 5.5$ & $15.6 \pm 0.7$ & $3.5 \pm 1.0$ & $0.8 \pm 0.8$ & $0.8 \pm 0.8$ & $0.0 \pm 0.0$ & $1.0 \pm 0.4$ & $0.0 \pm 0.0$ \\
\hline SLD & 3 & $27.3 \pm 2.5$ & $6.3 \pm 1.0$ & $3.0 \pm 2.3$ & $0.5 \pm 0.3$ & $1.8 \pm 0.9$ & $0.3 \pm 0.3$ & $0.3 \pm 0.3$ & $0.0 \pm 0.0$ \\
\hline $\mathrm{PnC}$ & 2 & $67.5 \pm 3.4$ & $34.5 \pm 1.1$ & $3.3 \pm 0.6^{*, \#}$ & $0.8 \pm 0.3$ & $0.8 \pm 0.5$ & $0.3 \pm 0.3$ & $0.0 \pm 0.0$ & $0.3 \pm 0.3$ \\
\hline Pn0 & 4 & $161.8 \pm 6.2$ & $77.2 \pm 1.5$ & $6.0 \pm 3.1^{*, \#}$ & $2.0 \pm 0.0$ & $1.0 \pm 0.7$ & $0.3 \pm 0.3$ & $0.3 \pm 0.3$ & $0.5 \pm 0.3$ \\
\hline \multicolumn{10}{|c|}{ Medullary reticular formation } \\
\hline LPGi & 4 & $24.7 \pm 0.6$ & $18.8 \pm 0.9$ & $2.0 \pm 0.7$ & $1.8 \pm 0.8$ & $0.3 \pm 0.3$ & $1.3 \pm 0.9$ & $0.5 \pm 0.5$ & $0.5 \pm 0.3$ \\
\hline DPGi & 4 & $13.3 \pm 0.5$ & $19.5 \pm 1.0$ & $8.8 \pm 1.3^{*, \#}$ & $4.5 \pm 0.3^{*, \#}$ & $0.3 \pm 0.3$ & $0.3 \pm 0.3$ & $0.3 \pm 0.3$ & $0.0 \pm 0.0$ \\
\hline $\mathrm{Gi}$ & 4 & $17.8 \pm 1.3$ & $9.6 \pm 0.5$ & $1.3 \pm 0.3^{*, \#}$ & $1.5 \pm 0.3^{*, \#}$ & $0.0 \pm 0.0$ & $0.3 \pm 0.3$ & $0.3 \pm 0.3$ & $0.0 \pm 0.0$ \\
\hline PCRt & 5 & $39.9 \pm 3.6$ & $18.5 \pm 1.6$ & $2.8 \pm 0.9$ & $1.5 \pm 0.5$ & $1.0 \pm 0.4$ & $0.8 \pm 0.5$ & $0.0 \pm 0.0$ & $0.0 \pm 0.0$ \\
\hline
\end{tabular}

Ipsi, Ipsilateral; Contra, contralateral. $n$, Number of sections counted for each structure; ${ }^{*} p<0.05$ versus PSC, ${ }^{\#} p<0.05$ versus PSD.

significant $(22.5 \pm 4.5$ vs $12.8 \pm 2.9$, Mann-Whitney $U$ test, $Z=$ $-1.588, p=0.11)$.

\section{VLPAG/dDpMe afferents specifically activated during PS hypersomnia}

Twelve CTb injection sites were localized at the border between the VLPAG and the dDpMe (Figs. 1, 2A). The presence of numerous c-FOS labeled (c-FOS+) neurons within the CTb injection sites in PSD animals indicates that the GABAergic PS-off neurons were effectively targeted (Fig. 2A1). In addition, 12 control injections sites were localized in structures surrounding the VLPAG/ dDpMe containing no or a few c-FOS labeled neurons in PSD animals (Fig. 1).

The distribution of c-FOS + neurons in PSC, PSD, and PSR animals (as illustrated in Fig. 2E) was similar to that described in our previous reports (Verret et al., 2003, 2005, 2006; Léger et al., 2009; Sapin et al., 2009, 2010; Clément et al., 2011). The distribution of retrogradely labeled neurons (Table 1) was also in line with previous 
works on the afferents to the VLPAG/ dDpMe region (Holstege et al., 1985; Behbehani, 1995; Rizvi et al., 1996; Dong and Swanson, 2006; Lu et al., 2006; Kaur et al., 2009; Hsieh et al., 2011). The largest number of $\mathrm{CTb}$-labeled $(\mathrm{CTb}+)$ neurons was observed in the bed nucleus of the stria terminalis (BST), the central nucleus of the amygdala (Ce) (Fig. 2F), the LH (Fig. $2 B, C$ ), the zona incerta (ZI) (Fig. 2C), the periaqueductal gray (PAG), the superior colliculus (SC), the DpMe, and the nucleus pontis oralis $(\mathrm{PnO})$.

A large number of $\mathrm{CTb} / \mathrm{c}-\mathrm{FOS}$ doublelabeled neurons ( $\mathrm{CTb} / \mathrm{c}-\mathrm{FOS}+$ ) was only seen in PSR animals (Table 1). Most of these cells were localized ipsilaterally to

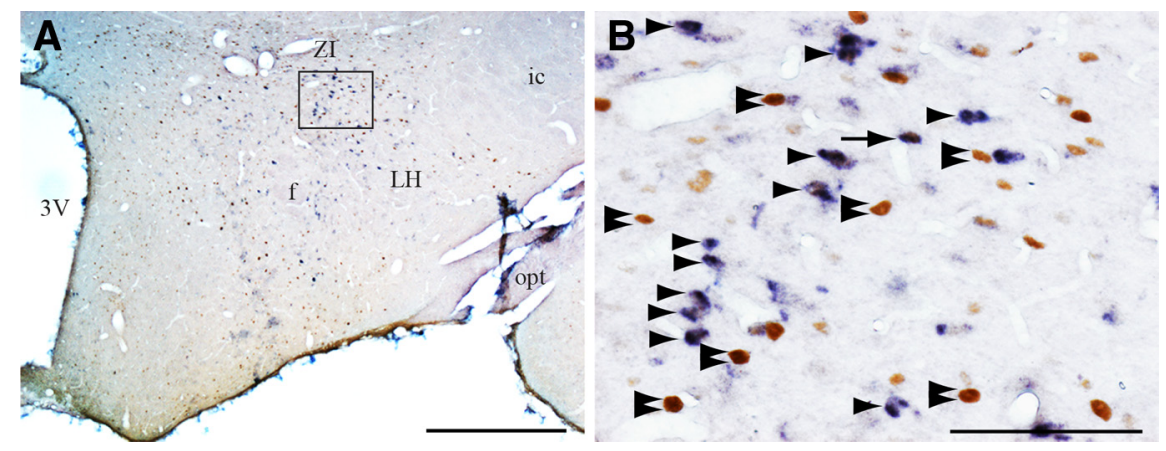

Figure 3. Neurotensin expressing neurons in the LH are not c-FOS + during PS hypersomnia. $\boldsymbol{A}$, Low-power photomicrograph of a double-stained section for neurotensin (dark blue diffuse cytoplasmic staining) and c-FOS (DAB brown nuclear staining) in a coronal section passing through the LH in a PSR animal. $\boldsymbol{B}$, Enlargement of the framed area in $\boldsymbol{A}$. Arrow point out c-FOS/ neurotensin + , arrowheads neurotensin + , and double arrowheads singly c-FOS + neurons. Scale bars: $\boldsymbol{A}, 500 \mu \mathrm{m} ; \boldsymbol{B}, 100 \mu \mathrm{m}$. 3V, Third ventricle; $f$, fornix; ic, internal capsule; opt, optic tract.

the CTb injection site in the posterior part

of the hypothalamus and the different subdivisions of the PAG (Table 1). The LH $(55.8 \pm 4)$ contained a very large, and the adjacent ZI $(27.5 \pm 5.8)$ a large number of $\mathrm{CTb} / \mathrm{c}$-FOS + cells in PSR animals compared with PSD and PSC ones $(p<0.05$ for each paired comparison) (Table 1, Fig. $2 B, C$ ). The doublelabeled neurons accounted for 13 and $7 \%$ of the total number of $\mathrm{CTb}+$ neurons in the LH and the ZI, respectively. The posterior hypothalamic area also contained a significant number of double-labeled neurons in PSR animals compared with the two other conditions (Table 1).

The rostromedial (RMPAG), dorsomedial (DMPAG), and to a minor extent the dorsolateral (DLPAG) PAG also contained a large number of double-labeled cells in PSR animals compared with the PSC and PSD ones ( $p<0.05$ for all paired comparison) (Table 1). The LPAG and VLPAG contained a large or substantial number of double-labeled cells compared with PSC animals not only in PSR but also in PSD animals $(p<0.05$ for all paired comparison) (Table 1). The percentage of CTb/c-FOS+ versus the total number of $\mathrm{CTb}+$ neurons was $12-18 \%$ in the dorsal and $8-6 \%$ in the ventral PAG subdivisions, respectively.

Finally, a substantial to small number of double-labeled neurons was seen in PSR animals in the DpMe, the DPGi, and the caudal $(\mathrm{PnC})$ and oral $(\mathrm{PnO})$ pontine reticular nuclei. The percentage of $\mathrm{CTb} / \mathrm{c}$-FOS + double-labeled cells over the total number of $\mathrm{CTb}+$ cells was $<6 \%$ in these structures except for the DPGi in which they surprisingly represented $60 \%$ of all $\mathrm{CTb}+$ neurons.

Importantly, the lateral preoptic area (including the extended ventrolateral preoptic area), the SLD, and the laterodorsal tegmental nucleus (LDTg), previously implicated in PS control, did not contain a significant number of double-labeled cells in PSR animals, although they all contained a substantial number of singly $\mathrm{CTb}+$ and singly c-FOS + neurons (Fig. 2D,E, Table 1 ).

The number of singly $\mathrm{CTb}+$ and $\mathrm{CTb} / \mathrm{c}-\mathrm{FOS}+$ neurons after the four control injection sites obtained in PSR rats (Fig. 1) was significantly smaller in several areas compared with VLPAG/ $\mathrm{dDpMe}$ injections. First, the number of $\mathrm{CTb}+$ neurons in all subdivisions of the PAG, as well as in the lateral parabrachial nucleus (LPB), the Kolliker-Füse nucleus (KF), the DpMe, the central gray of the pons, the SLD, and the lateral paragigantocellular reticular nucleus (LPGi) was significantly reduced compared with PSR animals $(p<0,05)$. For the two control sites localized more rostrally (AP, -6.3 ; Fig. 1 ), the number of $\mathrm{CTb}+$ neurons located in the central nucleus of the amygdala was smaller than for the VLPAG/dDpMe sites while it was larger for the control site located ventrally to the VLPAG/dDpMe. Importantly, although the total number of $\mathrm{CTb}+$ neurons counted in the LH and in the ZI was not different between the control and the VLPAG/dDpMe sites, the number of $\mathrm{CTb} / \mathrm{c}$-FOS doublelabeled cells was significantly reduced in control sites compared with VLPAG/dDpMe ones $(21.0 \pm 4.9$ vs $55.8 \pm 4.0$, MannWhitney $U$ test, $Z=-2.309, p=0.02$ for $\mathrm{LH}$ and $5.8 \pm 2.3 \mathrm{vs}$ $27.5 \pm 5.8$, Mann-Whitney $U$ test, $Z=-2.309, p=0.02$ for $Z \mathrm{I}$ ). The number of $\mathrm{CTb} / \mathrm{c}-\mathrm{FOS}+$ neurons was also significantly lower after control injections compared with VLPAG/dDpMe ones in all PAG subdivisions, the DPGi, and the posterior hypothalamic nucleus ( $p<0,05$ for all paired comparisons). These results indicate that the afferents activated during PS hypersomnia preferentially target the VLPAG/dDpMe rather than the adjacent regions.

\section{Contribution of the $\mathrm{MCH}$ neurons to the LH-VLPAG/dDpMe projection}

It has been previously demonstrated that $\sim 60 \%$ of the c-FOS + neurons localized in the LH after PS hypersomnia express the neuropeptide MCH (Verret et al., 2003; Hanriot et al., 2007). Therefore, to determine the contribution of the $\mathrm{MCH}$ neurons to the descending pathway from the LH to the VLPAG/dDpMe, we performed a triple labeling combining $\mathrm{MCH}$ and $\mathrm{CTb}$ immunofluorescence with c-FOS DAB immunostaining (Fig. 2B) in PSR animals with a CTb injection in the VLPAG/dDpMe $(n=4)$. We found that $44.1 \pm 5.4 \%$ of the $\mathrm{CTb} / \mathrm{c}$-FOS + cells localized in the LH express MCH (Fig. 2B-C). Since it has recently been shown that the LH contains a population of GABAergic neurons that express neurotensin but not MCH (Leinninger et al., 2009, 2011), we further determined whether part of the c-FOS + neurons located in the LH in PSR animals might include this population. We found out in PSR animals that $<5 \%$ of the c-FOS + neurons in the LH express neurotensin, and $<9 \%$ of neurotensin + cells of the $\mathrm{LH}$ are c-FOS+, eliminating this possibility (Fig. 3).

\section{Effect on PS of the inactivation of LH neurons}

Our tract tracing analysis (see above) clearly showed that the LH is the only structure containing a very large number of neurons activated during PS hypersomnia and projecting to the VLPAG/ $\mathrm{dDpMe}$. These neurons, in part $\mathrm{MCH}+$, could play a key role in PS control by means of an inhibition at the onset and during PS of the GABAergic PS-off neurons located in the VLPAG/dDpMe. To test this hypothesis, we determined the effect on sleep quantities from bilateral injections in the LH of two inhibitory com- 
A

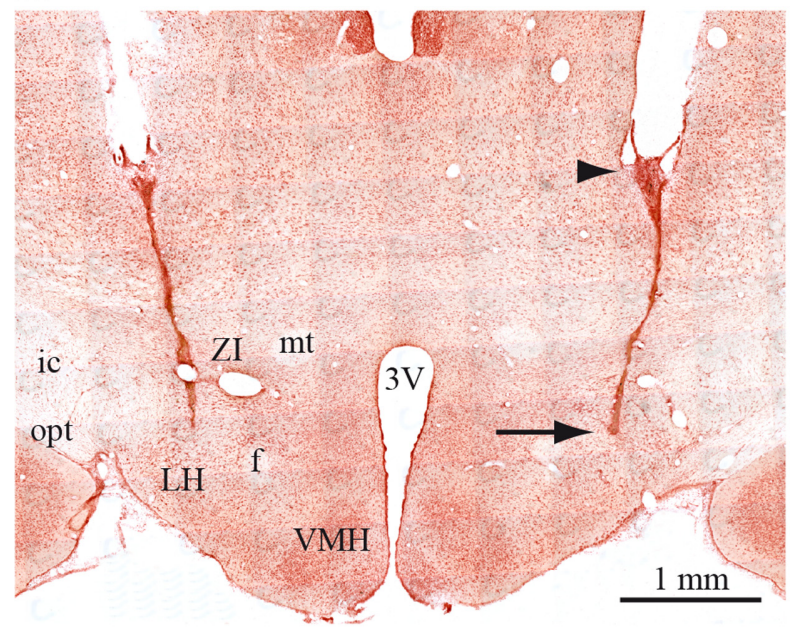

B

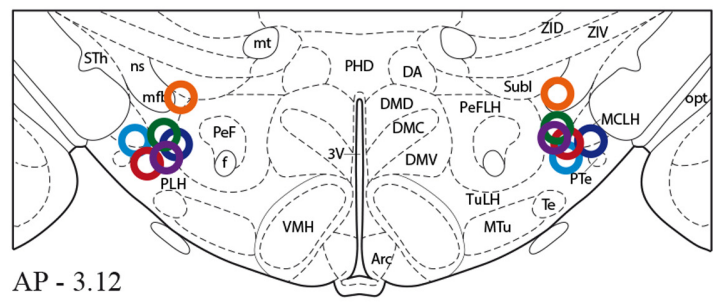

C
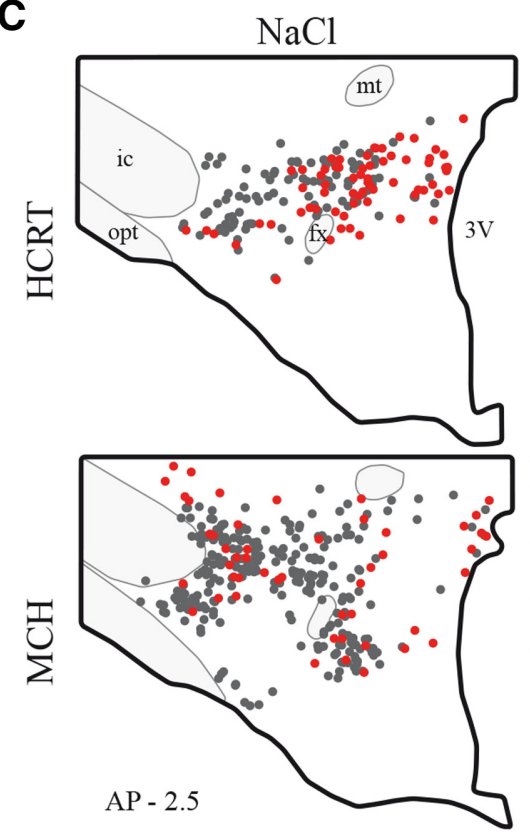

Muscimol
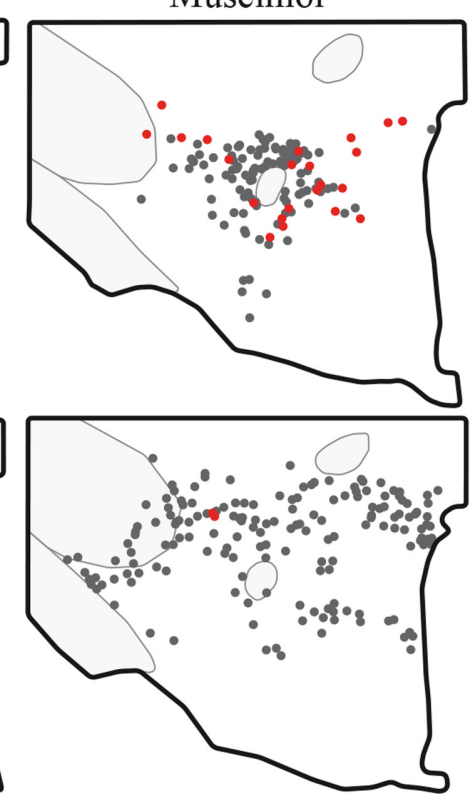

D

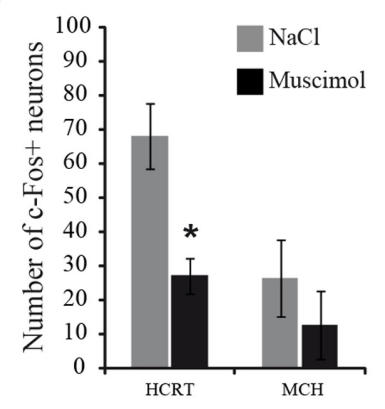

E

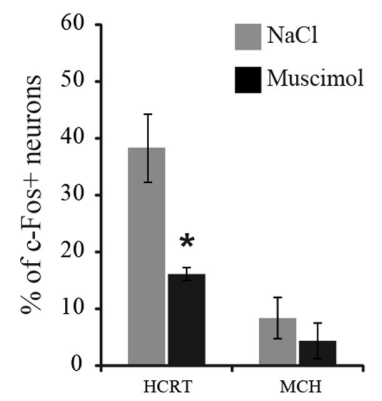

Figure 4. Localization of injection sites in the LH. $A$, Photomicrograph of a bilateral injection site within the LH as visualized on a neutral red counterstained section. A black arrow points out the extremity of the cannula and an arrowhead the tip of the guide cannula. B, All injection sites are illustrated by open circles with different colors on two atlas sections. Adapted from Paxinos (1997) and Watson Rat Brain atlas, fifth edition. C, Schematic drawings of sections illustrating in representative animals singly HCRT +, or MCH +, (gray dots), and C-FOS/HCRT +, or C-FOS/MCH + (red dots) neurons in animals perfused $3 \mathrm{~h}$ after $\mathrm{NaCl}$ or muscimol injection in the LH. The rostrocaudal level of the section is indicated in the bottom left corner (in $\mathrm{mm}$ from bregma). $\boldsymbol{D}$, Numbers (mean \pm SEM) of HCRT and MCH immunoreactive neurons expressing c $-\mathrm{FOS}$ in rats perfused $3 \mathrm{~h}$ after muscimol or NaCl treatments ( $n=4$ rats per group). $\boldsymbol{E}$, Percentages of HCRT and MCH immunoreactive neurons expressing c-FOS in animals perfused $3 \mathrm{~h}$ after muscimol and NaCl treatments ( $n=4$ per group). ${ }^{*} p<0.05 \mathrm{vs} \mathrm{NaCl}$ condition. $3 \mathrm{~V}$, Third ventricle; $\mathrm{f}$, fornix; ic, internal capsule; mt, mammillothalamic tract; opt, optic tract; VMH, ventromedial hypothalamic nucleus.

pounds, muscimol (a GABA $\mathrm{A}_{\mathrm{A}}$ agonist) and clonidine (an $\alpha-2$ adrenergic agonist). Muscimol was chosen for its ability to inhibit all neurons. We also tested the effect of clonidine, because, in basal condition, $\mathrm{MCH}$ neurons but not the intermingled wakeactive hypocretin neurons have been reported to express $\alpha-2$ adrenergic receptors (van den Pol et al., 2004; Uschakov et al., 2011).

In the eight animals used, all injection sites were localized in the LH (Fig. $4 A, B$ ). To confirm that the injections in the $\mathrm{LH}$ induced a local inhibition, we counted the number of hypocretin (HCRT) and $\mathrm{MCH}$ neurons expressing c-FOS in animals perfused $3 \mathrm{~h}$ after muscimol $(n=4)$ or $\mathrm{NaCl}(n=4)$ injections. As shown in Figure $4 C-E$, the injection of muscimol inside the $\mathrm{LH}$ induced a significant reduction of $60 \%$ in the number of HCRT neurons expressing c-FOS compared with $\mathrm{NaCl}$ (Mann-Whitney $U$ test, $Z=-2.309, p=0.02$ ). The number of $\mathrm{MCH} / \mathrm{c}-\mathrm{FOS}+$ neurons, already low following $\mathrm{NaCl}$, was slightly but not significantly lowered after muscimol injection (Mann-Whitney $U$ test, $Z=-0.722, p=0.47)$.

Muscimol injection in the $\mathrm{LH}(n=8)$ induced a significant increase in SWS quantities during $14 \mathrm{~h}$ compared with $\mathrm{NaCl}$ (Fig. $5 A, C)$. The effect was due to an increase in the number and duration of SWS episodes and a decrease in waking quantities (Fig. 5D,E). SWS latency was not modified compared with $\mathrm{NaCl}$ $(9.7 \pm 2.5 \mathrm{~min}$ vs $8.2 \pm 1.5 \mathrm{~min}$, Wilcoxon signed-rank test, $Z=$ $-0.42, p=0.67)$. Although the animals spent $>80 \%$ of their time in SWS during the first $6 \mathrm{~h}$, PS was absent (Fig. $5 A, B$ ). PS latency was $389.7 \pm 14.8$ min after muscimol injection compared with 

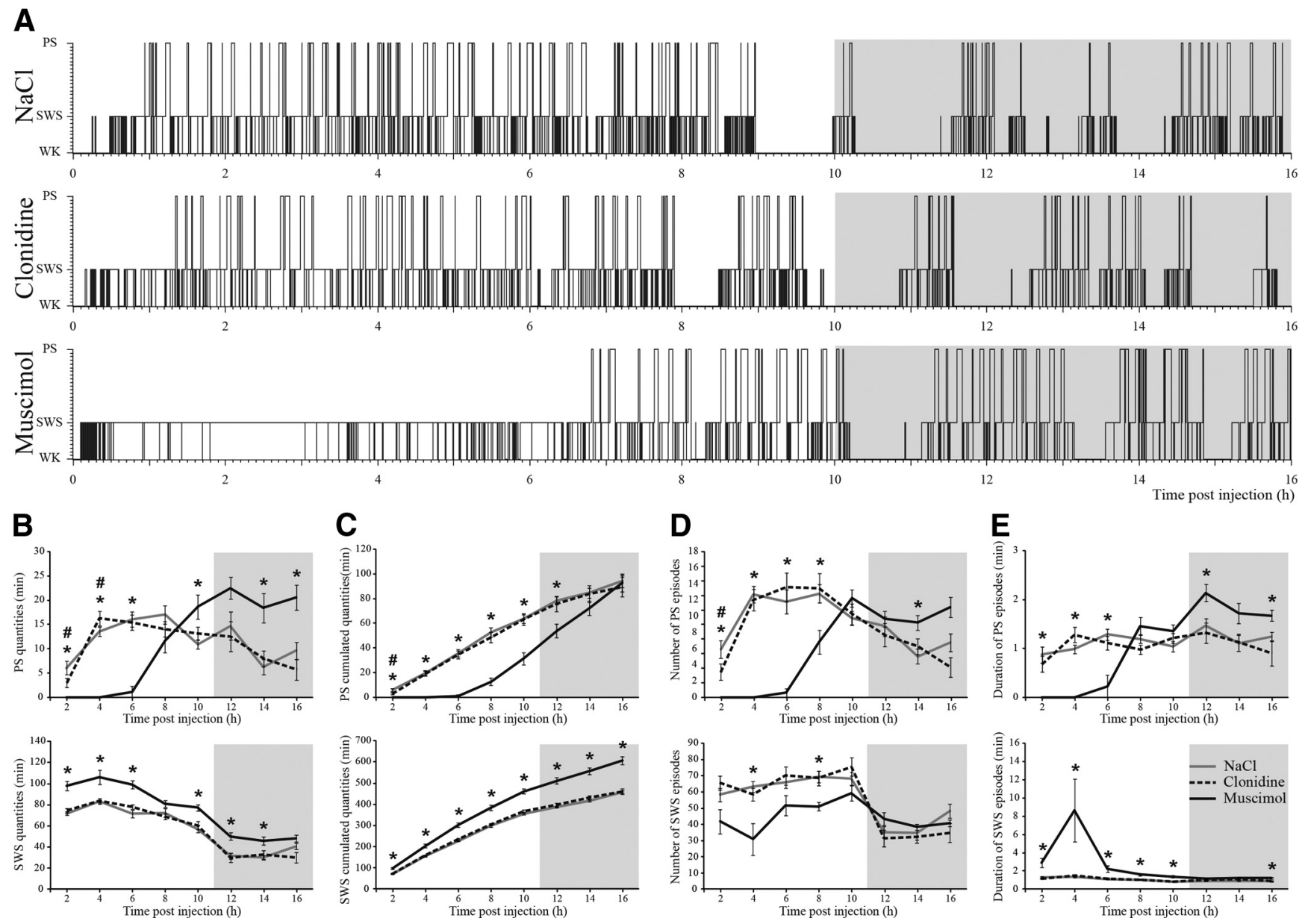

Figure 5. Pharmacological inactivation of LH neurons inhibits PS. A, Hypnograms illustrating the organization of the sleep-waking cycle during the $16 \mathrm{~h}$ (between 10:00 A.M. and 2:00 A.M.) following an injection of $\mathrm{NaCl}$, clonidine, or muscimol in the $\mathrm{LH}$ in a representative animal. A gray background differentiates the dark period. $\boldsymbol{B}-\boldsymbol{E}$, Quantitative analysis of sleep by $2 \mathrm{~h}$ blocks during the $16 \mathrm{~h}$ after muscimol (black lines), clonidine (black dashed lines), and $\mathrm{NaCl}$ (gray lines) application in $\mathrm{LH}$. The quantities per $2 \mathrm{~h}$ blocks $(\boldsymbol{B})$, the cumulated quantities across the $16 \mathrm{~h}(\boldsymbol{C})$, the number of episodes $(\boldsymbol{D})$, and the mean duration of episodes $(\boldsymbol{E})$ are given for PS and SWS. For all graphs, $n=8$ animals per group, values are mean \pm SEM and ${ }^{*} p<0.05$ between muscimol and NaCl, ${ }^{\#} p<$ 0.05 between clonidine and $\mathrm{NaCl}$.

$67.5 \pm 7.1 \mathrm{~min}$ for $\mathrm{NaCl}$ (Wilcoxon signed-rank test, $Z=$ $-2.521, p=0.01)$. Between 6 and $8 \mathrm{~h}$ after injection, PS episodes reappeared progressively. Then, between 8 and $16 \mathrm{~h}$ after muscimol injection, the amount of PS significantly increased compared with $\mathrm{NaCl}$ (Fig. 5A,B). This increase allowed muscimol-treated animals to recover the PS quantities lost during the first $6 \mathrm{~h}$ compared with $\mathrm{NaCl}$ as reflected by PS-cumulated values (92.9 \pm $7.4 \mathrm{~min}$ vs $94.3 \pm 5.1 \mathrm{~min} 16 \mathrm{~h}$ after injection, Wilcoxon signedrank test, $Z=-0.7, p=0.48$ ) (Fig. $5 C$ ). The increase in PS quantities during the $8-16 \mathrm{~h}$ period was due to an increase in the number and duration of PS episodes (Fig. 5D,E).

During the first $2 \mathrm{~h}$ after clonidine injection $(n=8)$, PS quantities were reduced compared with $\mathrm{NaCl}(3 \pm 0.9 \mathrm{~min}$ vs $6.1 \pm 1.4$ min, Wilcoxon signed-rank test, $Z=-2.38, p=0.02$ ) (Fig. $5 B, C)$. This decrease was due to a reduction in the number of PS episodes ( $3.5 \pm 1.1$ vs $6.6 \pm 1.2$, Wilcoxon signed-rank test, $Z=$ $-2.1, p=0.04)$ but not of their duration $(0.7 \pm 0.2 \mathrm{~min}$ vs $0.9 \pm$ $0.2 \mathrm{~min}$, Wilcoxon signed-rank test, $Z=-0.98, p=0.33$ ) (Fig. $5 D, E)$. PS latency was increased by $53.5 \%$ after clonidine injection compared with $\mathrm{NaCl}$ (from $67.5 \pm 7.1 \mathrm{~min}$ to $103.6 \pm 9.5$ min, Wilcoxon signed-rank test, $Z=-2.366, p=0.02$ ) (Fig. $5 F$ ). Then, between 2 and $4 \mathrm{~h}$ after clonidine injection, PS quantities were significantly increased compared with $\mathrm{NaCl}(16.3 \pm 1.5 \mathrm{~min}$ vs $13.6 \pm 0.9 \mathrm{~min}$ for $\mathrm{NaCl}$, Wilcoxon signed-rank test, $Z=-2.1$, $p=0.04)$. After $4 \mathrm{~h}$, PS cumulated values were no longer different between $\mathrm{NaCl}$ and clonidine treated animals $(19.6 \pm 2 \mathrm{~min}$ vs $19.3 \pm 2.1 \mathrm{~min}$, respectively). SWS (Fig. $5 B-E$ ) and waking quantities were not affected by clonidine treatment although SWS latency was decreased by $46.5 \%$ compared with $\mathrm{NaCl}$ (from $8.2 \pm$ $1.5 \mathrm{~min}$ to $4.4 \pm 1.2 \mathrm{~min}$, Wilcoxon signed-rank test, $Z=-2.028$, $p=0.04)$.

\section{Effect of LH inactivation on c-FOS expression in}

VLPAG/dDpMe GABAergic neurons projecting to the SLD

To determine whether VLPAG/dDpMe GABAergic neurons play a role in the suppression of PS induced by muscimol application in the $\mathrm{LH}$, we counted the number of c-FOS + neurons expressing gad67 mRNA in the VLPAG/dDpMe in rats perfused $3 \mathrm{~h}$ after muscimol $(n=4)$ or $\mathrm{NaCl}(n=4)$ injections. During the $3 \mathrm{~h}$ following muscimol injection, animals spent $96.0 \pm 1 \%$ of their time in SWS (vs $57.9 \pm 5 \%$ for NaCl, Mann-Whitney $U$ test, $Z=$ $-2.309, p=0.02)$ and PS was totally suppressed $(0 \pm 0 \%$ vs $7.5 \pm$ $0.6 \%$ for $\mathrm{NaCl}$, Mann-Whitney $U$ test, $Z=-2.309, p=0.02$ ). As illustrated in Figure $6 A-C$, the number of c-FOS/gad67 doublestained neurons was 3.7 times higher in the VLPAG (MannWhitney $U$ test, $Z=-2.309, p=0.02$ ) and 8.2 times higher in the dDpMe (Mann-Whitney $U$ test, $Z=-2.309, p=0.02$ ) after muscimol compared with $\mathrm{NaCl}$ injections. These neurons repre- 

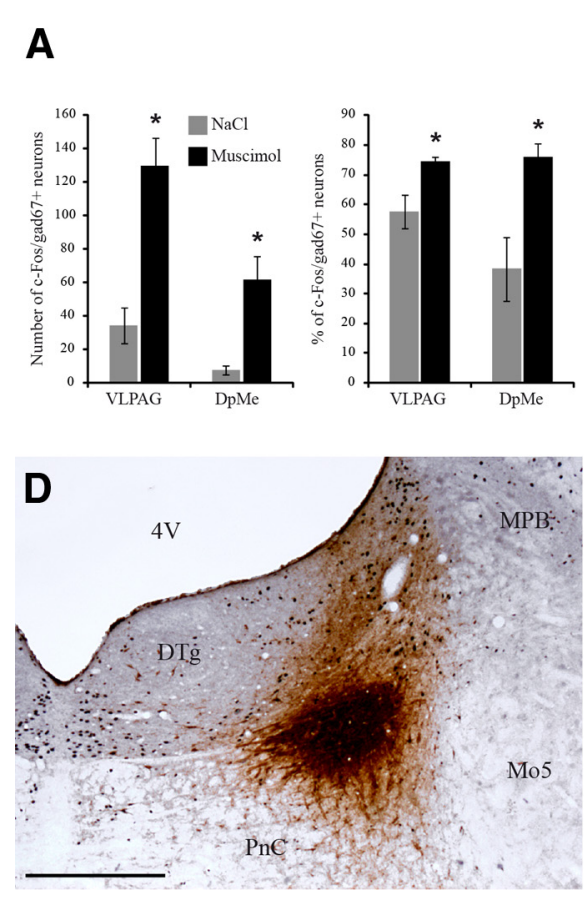

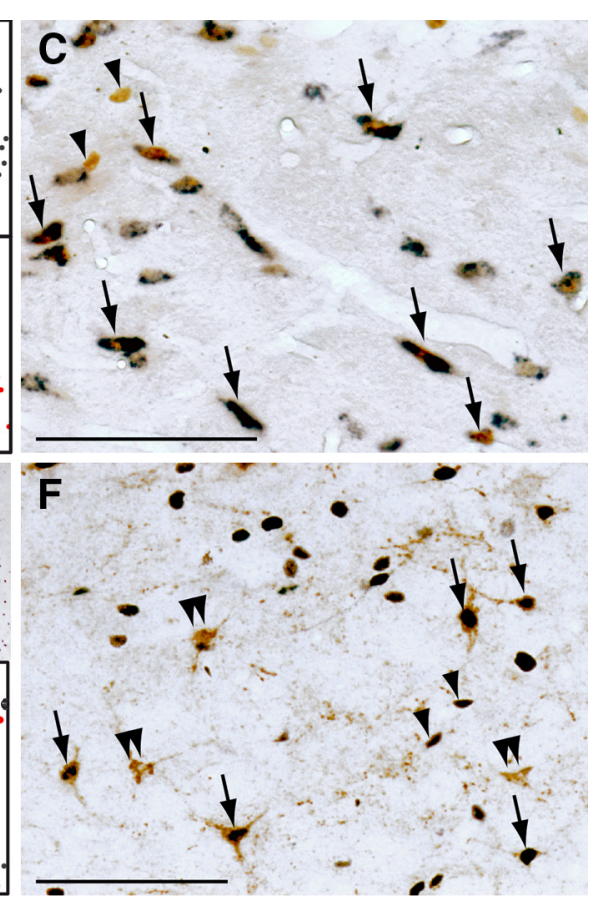

Figure 6. Muscimol inhibition of LH induces an activation of VLPAG/dDpMe GABAergic neurons projecting to the SLD. $A-F$, Neurons visualized $3 \mathrm{~h}$ after muscimol or NaCl injection in the $L$ H. $\boldsymbol{A}$, Histograms showing the number and percentage (over the total number of c-FOS + neurons) of c-FOS/gad67+ neurons in the VLPAG and dDpMe in animals after injections of NaCl or muscimol in the LH ( $n=4$ per group). Values are mean \pm SEM and ${ }^{*} p<0.05$ vs NaCl. $\boldsymbol{B}$, Low-power photomicrograph (left) of a double stained section for gad67 (dark blue diffuse cytoplasmic staining) and c-FOS (DAB brown nuclear staining) in an animal that received a muscimol injection in the LH. The same section is shown as a drawing in the lower right corner with singly c-FOS + neurons illustrated by gray dots and double-labeled c-FOS/gad67+ neurons by red dots. The number of double-labeled neurons is much higher after muscimol than after $\mathrm{NaCl}$ (top right). The framed area in the photomicrograph and the drawing is enlarged in C. Arrows point out c-FOS/gad67 double-labeled neurons and arrowheads C-FOS singly labeled neurons. D, Low-power photomicrograph showing the localization of a CTb injection site within the SLD. E, Low-power photomicrograph of a section double-stained with CTb and C-FOS and its schematic drawing illustrating CTb + (brown cytoplasmic labeling, open circles), c-FOS + (black nuclear staining, gray dots), and (Tb/c-FOS + (red dots) neurons in the VLPAG/dDpMe in an animal with a CTb injection in the SLD perfused $3 \mathrm{~h}$ after muscimol application in the LH. The framed area in $\boldsymbol{E}$ is enlarged in $\boldsymbol{F}$. Arrows point out $\mathrm{CTb} / \mathrm{c}-\mathrm{FOS}+$, arrowheads singly $\mathrm{C}-\mathrm{FOS}+$, and double arrowheads singly $\mathrm{CTb}+$ labeled neurons. The same animal is represented in $\boldsymbol{D}-\boldsymbol{F}$. Scale bars: $\boldsymbol{B}, \boldsymbol{D}, \boldsymbol{E}, 500 \mu \mathrm{m} ; \boldsymbol{C}, \boldsymbol{F}, 100 \mu \mathrm{m}$. 4N, Trochlear nucleus; $4 \mathrm{~V}$, fourth ventricle; Aq, aqueduct; mlf, medial longitudinal fasciculus; Mo5, motor trigeminal nucleus; MPB, medial parabrachial nucleus.

sented $75 \%$ of the total number of c-FOS + neurons. Additionally, in the two rats with a muscimol injection in the $\mathrm{LH}$ and a CTb injection in the SLD (Fig. 6D), a large number of CTb+ neurons were observed in the VLPAG/dDpMe area (Fig. $6 E, F$ ) as already reported (Boissard et al., 2003) and 30\% of these CTb+ neurons expressed c-FOS (Fig. 6E,F).

\section{Discussion}

Based on an exhaustive analysis of the afferents to the VLPAG/ $\mathrm{dDpMe}$ activated during selective PS deprivation and hypersomnia, we show for the first time that the $\mathrm{LH}$ is the only structure containing a very large number of neurons activated during PS and projecting to the VLPAG/dDpMe. We further reveal that $44 \%$ of these neurons express the neuropeptide $\mathrm{MCH}$. We then show that muscimol or clonidine injection in the LH induces an inhibition of PS. We finally demonstrate that a large number of VLPAG/dDpMe neurons activated after muscimol injection in the LH are GABAergic and project to the SLD.

\section{Methodological considerations}

In the present study, we used c-FOS as a marker of neuronal activation given that, even if it is not a perfect marker (Kovács, 2008), it is still the best available to extensively map activated neurons. Indeed, during the last 15 years, c-FOS has been widely used by many groups to identify the neuronal network controlling the sleep/waking cycle (Yamuy et al., 1993; Sherin et al., 1996; Maloney et al., 1999, 2000, 2002; Morales et al., 1999, 2006; Boissard et al., 2002; Verret et al., 2003, 2005, 2006; Modirrousta et al.,
2005; Lu et al., 2006; Léger et al., 2009; Sapin et al., 2009, 2010; Clément et al., 2011; Hsieh et al., 2011). Furthermore, electrophysiological recordings of neurons performed so far in structures containing c-FOS+ neurons in the PSR condition confirmed the presence of PS-on neurons (Koyama et al., 2003; Luppi et al., 2004, 2012; Goutagny et al., 2005, 2008; Hassani et al., 2009, 2010; Sirieix et al., 2012).

\section{$\mathrm{MCH} / \mathrm{GABAergic}$ neurons of the $\mathrm{LH}$ inactivate}

\section{VLPAG/dDpMe GABAergic PS-off neurons at the onset and} during PS

We show in the present study that, specifically during PS hypersomnia, the LH contains a very large number of $\mathrm{CTb} / \mathrm{c}-\mathrm{FOS}$ double-labeled cells after a CTb injection in the VLPAG/dDpMe. We further show that $44 \%$ of these neurons express $\mathrm{MCH}$. In agreement with our results, a large number of $\mathrm{MCH}$ immunoreactive fibers and $\mathrm{MCH}$ receptors 1 has been observed in the VLPAG/dDpMe region (Bittencourt et al., 1992; Hervieu et al., 2000 ). We previously showed that 60 and $75 \%$ of the numerous c-FOS+ neurons located in the LH during PS hypersomnia are $\mathrm{MCH}+$ and gad67+, respectively (Verret et al., 2003; Sapin et al., 2010). We further demonstrated, combining $\mathrm{MCH}$ immunohistochemistry with gad67 in situ hybridization, that $85 \%$ of the $\mathrm{MCH}$ neurons are gad67+ and therefore likely GABAergic (Sapin et al., 2010). Electrophysiological recordings in the LH coupled with juxtacellular labeling confirmed that $\mathrm{MCH}+$ neurons are specifically active during PS (Hassani et al., 2009). From the present and previous data, it can therefore be concluded that 
PS-on MCH/GABAergic neurons of the LH heavily project to the VLPAG/dDpMe.

To determine the function of this pathway in PS control, we inactivated all LH neurons with muscimol (a GABAa agonist) or only those bearing $\alpha-2$ adrenergic receptors using clonidine. We found that muscimol and to a lesser degree clonidine bilateral injections in the LH induce an inhibition of PS with or without an increase in SWS quantities, respectively. Our results are in line with a previous study in cats that reported a strong SWS hypersomnia with a total suppression of PS after muscimol injection in the LH (Lin et al., 1989). The fact that both compounds inhibit PS and that muscimol also inhibits waking could be due to a restricted expression of $\alpha 2$ adrenergic receptors on LH neurons implicated in PS control compared with a ubiquitous expression of GABAa receptors on all $\mathrm{LH}$ neurons including wake-active ones. Nevertheless, a neuroanatomical study demonstrated that $\alpha-1$ and $\alpha-2$ adrenergic receptors are expressed in 21 and $16 \%$ of the wake promoting HCRT neurons (Piper et al., 2000; Estabrooke et al., 2001; Adamantidis et al., 2007) and 1.5 and 15\% of the MCH neurons, respectively (Modirrousta et al., 2005). However, in vitro studies showed that in basal condition, the HCRT neurons are excited by noradrenaline and not affected by clonidine (Bayer et al., 2005; Grivel et al., 2005; Uschakov et al., 2011) while the MCH/GABAergic PS-on neurons are hyperpolarized by noradrenaline and clonidine applications (van den Pol et al., 2004). Moreover, it is unlikely that HCRT neurons are inhibited by clonidine in our experiments since SWS quantities were not increased like after optogenetic inhibition of HCRT neurons (Tsunematsu et al., 2011). In view of all these results, the observed suppression of PS by clonidine could result from the inhibition of the $\mathrm{MCH} / \mathrm{GABAergic}$ PS-on neurons although it remains to be ruled out that other types of LH neurons are not also inhibited by clonidine and are therefore involved in PS control.

We further showed that after muscimol injection in the $\mathrm{LH}$, the VLPAG/dDpMe region contains a large number of c-FOS/ gad67+ and of c-FOS/CTb + neurons in animals with a CTb injection in the SLD. Our results first indicate that the activation of PS-on neurons localized in the LH, in part MCH/GABAergic, is a necessary step for PS to occur. They further suggest that these neurons control PS onset and maintenance by means of their direct inhibitory projection to VLPAG/dDpMe PS-off GABAergic neurons. More generally, it can be proposed that PS-on neurons of the LH constitute a master generator of PS that controls a slaved generator located in the brainstem. It is indeed well known that the brainstem is necessary and sufficient to generate PS since this state is still present after the removal of the forebrain (Jouvet, 1962). To reconcile these and the present results, we therefore propose that, in intact animals, the activation of LH PS-on neurons trigger PS by directly inactivating the VLPAG/dDpMe PSoff GABAergic neurons inducing the disinhibition of the SLD glutamatergic PS-on neurons and therefore the state of PS. In animals with an ablation of the hypothalamic generator, brainstem PS-on neurons, localized in the PAG and/or the SLD, would be able to take over brainstem PS-off neurons to generate PS.

\section{PS control by other structures than the LH projecting to the VLPAG/dDpMe}

After CTb injection in the VLPAG/dDPMe, the dorsal and dorsolateral PAG contained a large number of $\mathrm{CTb} / \mathrm{c}-\mathrm{FOS}$ doublelabeled neurons specifically in PSR rats while the lateral and ventrolateral PAG contained such cells both in PSD and PSR animals. We previously showed that $50 \%$ of the VLPAG c-FOS labeled neurons in PSR animals expressed gad67 and are there- fore GABAergic. In contrast, the great majority of the c-FOS labeled neurons located in LPAG, DLPAG, and DMPAG in PSD and PSR animals did not express gad67 (Sapin et al., 2009) and could be glutamatergic (Clements et al., 1987). Altogether, these and the present results suggest that putatively glutamatergic and GABAergic PS-off and PS-on neurons located in the different subdivisions of the PAG might control the activity of the PS-off GABAergic neurons in the VLPAG/dDpMe. They more generally confirm as proposed previously (Luppi et al., 2012) that it constitutes a key structure for PS control, since the PAG contains both PS-off and PS-on neurons with probable reciprocal interconnections.

We also importantly found that, although the SLD contains a significant number of $\mathrm{CTb}+$ neurons after $\mathrm{CTb}$ injection in the VLPAG/dDpMe, they did not express c-FOS in all groups of animals. We previously demonstrated that the numerous c-FOS+ neurons localized in the SLD during PS hypersomnia are not GABAergic (Sapin et al., 2009). We further showed that most of them are glutamatergic (Clément et al., 2011). Altogether, our results strongly suggest that the SLD neurons projecting to the VLPAG/dDpMe region are not GABAergic PS-on neurons. They are therefore not in favor of the hypothesis that a flip-flop switch, between PS-on GABAergic neurons located in the SLD and GABAergic PS-off neurons located in the VLPAG/dDpMe, controls PS as previously hypothesized (Lu et al., 2006). The discrepancies between ours and the data of Lu et al. could be due to the fact that different methods were used to induce PS hypersomnia.

We also did not find $\mathrm{CTb} / \mathrm{c}-\mathrm{FOS}$ double labeled neurons in the lateral preoptic area (LPO) including the extended VLPO during PS hypersomnia although both c-FOS and CTb singly labeled neurons were present in this structure. These results are in line with another study showing that the number of VLPO neurons projecting to the VLPAG and expressing c-FOS during PShypersomnia does not correlate with PS quantities (Hsieh et al., 2011). They are not in favor of a control of PS-off GABAergic neurons of the VLPAG/dDpMe by PS-on GABAergic neurons located in the extended VLPO (Lu et al., 2006).

In summary, our results indicate that PS-on neurons, in part $\mathrm{MCH} / \mathrm{GABAergic}$, located in the $\mathrm{LH}$, constitute a master generator of PS. They further strongly suggest that these neurons control PS onset and maintenance via inhibitory projections to VLPAG/dDpMe GABAergic PS-off neurons.

\section{References}

Adamantidis AR, Zhang F, Aravanis AM, Deisseroth K, de Lecea L (2007) Neural substrates of awakening probed with optogenetic control of hypocretin neurons. Nature 450:420-424. CrossRef Medline

Bayer L, Eggermann E, Serafin M, Grivel J, Machard D, Muhlethaler M, Jones BE (2005) Opposite effects of noradrenaline and acetylcholine upon hypocretin/orexin versus melanin concentrating hormone neurons in rat hypothalamic slices. Neuroscience 130:807-811. CrossRef Medline

Behbehani MM (1995) Functional characteristics of the midbrain periaqueductal gray. Prog Neurobiol 46:575-605. CrossRef Medline

Bittencourt JC, Presse F, Arias C, Peto C, Vaughan J, Nahon JL, Vale W, Sawchenko PE (1992) The melanin-concentrating hormone system of the rat brain: an immuno- and hybridization histochemical characterization. J Comp Neurol 319:218-245. CrossRef Medline

Boissard R, Gervasoni D, Schmidt MH, Barbagli B, Fort P, Luppi PH (2002) The rat ponto-medullary network responsible for paradoxical sleep onset and maintenance: a combined microinjection and functional neuroanatomical study. Eur J Neurosci 16:1959-1973. CrossRef Medline

Boissard R, Fort P, Gervasoni D, Barbagli B, Luppi PH (2003) Localization of the GABAergic and non-GABAergic neurons projecting to the sublaterodorsal nucleus and potentially gating paradoxical sleep onset. Eur J Neurosci 18:1627-1639. CrossRef Medline

Clément O, Sapin E, Bérod A, Fort P, Luppi PH (2011) Evidence that neu- 
rons of the sublaterodorsal tegmental nucleus triggering paradoxical (REM) sleep are glutamatergic. Sleep 34:419-423. Medline

Clements JR, Madl JE, Johnson RL, Larson AA, Beitz AJ (1987) Localization of glutamate, glutaminase, aspartate and aspartate aminotransferase in the rat midbrain periaqueductal gray. Exp Brain Res 67:594-602. Medline

Crochet S, Onoe H, Sakai K (2006) A potent non-monoaminergic paradoxical sleep inhibitory system: a reverse microdialysis and single-unit recording study. Eur J Neurosci 24:1404-1412. CrossRef Medline

Dong HW, Swanson LW (2006) Projections from bed nuclei of the stria terminalis, dorsomedial nucleus: implications for cerebral hemisphere integration of neuroendocrine, autonomic, and drinking responses. J Comp Neurol 494:75-107. CrossRef Medline

Estabrooke IV, McCarthy MT, Ko E, Chou TC, Chemelli RM, Yanagisawa M, Saper CB, Scammell TE (2001) Fos expression in orexin neurons varies with behavioral state. J Neurosci 21:1656-1662. Medline

Goutagny R, Luppi PH, Salvert D, Gervasoni D, Fort P (2005) GABAergic control of hypothalamic melanin-concentrating hormone-containing neurons across the sleep-waking cycle. Neuroreport 16:1069-1073. CrossRef Medline

Goutagny R, Luppi PH, Salvert D, Lapray D, Gervasoni D, Fort P (2008) Role of the dorsal paragigantocellular reticular nucleus in paradoxical (rapid eye movement) sleep generation: a combined electrophysiological and anatomical study in the rat. Neuroscience 152:849-857. CrossRef Medline

Grivel J, Cvetkovic V, Bayer L, Machard D, Tobler I, Mühlethaler M, Serafin M (2005) The wake-promoting hypocretin/orexin neurons change their response to noradrenaline after sleep deprivation. J Neurosci 25:41274130. CrossRef Medline

Hanriot L, Camargo N, Courau AC, Leger L, Luppi PH, Peyron C (2007) Characterization of the melanin-concentrating hormone neurons activated during paradoxical sleep hypersomnia in rats. J Comp Neurol 505: 147-157. CrossRef Medline

Hassani OK, Lee MG, Jones BE (2009) Melanin-concentrating hormone neurons discharge in a reciprocal manner to orexin neurons across the sleep-wake cycle. Proc Natl Acad Sci U S A 106:2418-2422. CrossRef Medline

Hassani OK, Henny P, Lee MG, Jones BE (2010) GABAergic neurons intermingled with orexin and $\mathrm{MCH}$ neurons in the lateral hypothalamus discharge maximally during sleep. Eur J Neurosci 32:448-457. CrossRef Medline

Hervieu GJ, Cluderay JE, Harrison D, Meakin J, Maycox P, Nasir S, Leslie RA (2000) The distribution of the mRNA and protein products of the melanin-concentrating hormone $(\mathrm{MCH})$ receptor gene, slc-1, in the central nervous system of the rat. Eur J Neurosci 12:1194-1216. CrossRef Medline

Holstege G, Meiners L, Tan K (1985) Projections of the bed nucleus of the stria terminalis to the mesencephalon, pons, and medulla oblongata in the cat. Exp Brain Res 58:379-391. Medline

Hsieh KC, Gvilia I, Kumar S, Uschakov A, McGinty D, Alam MN, Szymusiak R (2011) c-Fos expression in neurons projecting from the preoptic and lateral hypothalamic areas to the ventrolateral periaqueductal gray in relation to sleep states. Neuroscience 188:55-67. CrossRef Medline

Jouvet M (1962) Recherches sur les structures nerveuses et les mecanismes responsables des differentes phases du sommeil physiologique. Arch Ital Biol 100:125-206. Medline

Kaur S, Thankachan S, Begum S, Liu M, Blanco-Centurion C, Shiromani PJ (2009) Hypocretin-2 saporin lesions of the ventrolateral periaquaductal gray (vlPAG) increase REM sleep in hypocretin knockout mice. PLoS One 4:e6346. CrossRef Medline

Kovács KJ (2008) Measurement of immediate-early gene activation- c-fos and beyond. J Neuroendocrinol 20:665-672. CrossRef Medline

Koyama Y, Takahashi K, Kodama T, Kayama Y (2003) State-dependent activity of neurons in the perifornical hypothalamic area during sleep and waking. Neuroscience 119:1209-1219. CrossRef Medline

Krenzer M, Anaclet C, Vetrivelan R, Wang N, Vong L, Lowell BB, Fuller PM, Lu J (2011) Brainstem and spinal cord circuitry regulating REM sleep and muscle atonia. PLoS One 6:e24998. CrossRef Medline

Léger L, Goutagny R, Sapin E, Salvert D, Fort P, Luppi PH (2009) Noradrenergic neurons expressing Fos during waking and paradoxical sleep deprivation in the rat. J Chem Neuroanat 37:149-157. CrossRef Medline

Leinninger GM, Jo YH, Leshan RL, Louis GW, Yang H, Barrera JG, Wilson H,
Opland DM, Faouzi MA, Gong Y, Jones JC, Rhodes CJ, Chua S Jr, Diano S, Horvath TL, Seeley RJ, Becker JB, Münzberg H, Myers MG Jr (2009) Leptin acts via leptin receptor-expressing lateral hypothalamic neurons to modulate the mesolimbic dopamine system and suppress feeding. Cell metabolism 10:89-98. CrossRef Medline

Leinninger GM, Opland DM, Jo YH, Faouzi M, Christensen L, Cappellucci LA, Rhodes CJ, Gnegy ME, Becker JB, Pothos EN, Seasholtz AF, Thompson RC, Myers MG Jr (2011) Leptin action via neurotensin neurons controls orexin, the mesolimbic dopamine system and energy balance. Cell metabolism 14:313-323. CrossRef Medline

Lin JS, Sakai K, Vanni-Mercier G, Jouvet M (1989) A critical role of the posterior hypothalamus in the mechanisms of wakefulness determined by microinjection of muscimol in freely moving cats. Brain Res 479:225-240. CrossRef Medline

Lu J, Sherman D, Devor M, Saper CB (2006) A putative flip-flop switch for control of REM sleep. Nature 441:589-594. CrossRef Medline

Luppi PH, Sakai K, Fort P, Salvert D, Jouvet M (1988) The nuclei of origin of monoaminergic, peptidergic, and cholinergic afferents to the cat nucleus reticularis magnocellularis: a double-labeling study with cholera toxin as a retrograde tracer. J Comp Neurol 277:1-20. CrossRef Medline

Luppi PH, Boissard R, Gervasoni D, Verret L, Goutagny R, Peyron C, Salvert D, Leger L, Barbagli B, Fort P (2004) The network responsible for paradoxical sleep onset and maintenance: a new theory based on the headrestrained rat model. In: Sleep: circuits and function (Luppi PH, ed), p 272. Boca Raton, FL: CRC.

Luppi PH, Clement O, Sapin E, Peyron C, Gervasoni D, Léger L, Fort P (2012) Brainstem mechanisms of paradoxical (REM) sleep generation. Pflugers Arch 463:43-52. CrossRef Medline

Maloney KJ, Mainville L, Jones BE (1999) Differential c-Fos expression in cholinergic, monoaminergic, and GABAergic cell groups of the pontomesencephalic tegmentum after paradoxical sleep deprivation and recovery. J Neurosci 19:3057-3072. Medline

Maloney KJ, Mainville L, Jones BE (2000) c-Fos expression in GABAergic, serotonergic, and other neurons of the pontomedullary reticular formation and raphe after paradoxical sleep deprivation and recovery. J Neurosci 20:4669-4679. Medline

Maloney KJ, Mainville L, Jones BE (2002) c-Fos expression in dopaminergic and GABAergic neurons of the ventral mesencephalic tegmentum after paradoxical sleep deprivation and recovery. Eur J Neurosci 15:774-778. CrossRef Medline

Modirrousta M, Mainville L, Jones BE (2005) Orexin and MCH neurons express c-Fos differently after sleep deprivation vs. recovery and bear different adrenergic receptors. Eur J Neurosci 21:2807-2816. CrossRef Medline

Morales FR, Sampogna S, Yamuy J, Chase MH (1999) c-fos expression in brainstem premotor interneurons during cholinergically induced active sleep in the cat. J Neurosci 19:9508-9518. Medline

Morales FR, Sampogna S, Rampon C, Luppi PH, Chase MH (2006) Brainstem glycinergic neurons and their activation during active (rapid eye movement) sleep in the cat. Neuroscience 142:37-47. CrossRef Medline

Paxinos G, Watson C (1998) The rat brain in stereotaxic coordinates, 4th edition. San Diego: Academic.

Piper DC, Upton N, Smith MI, Hunter AJ (2000) The novel brain neuropeptide, orexin-A, modulates the sleep-wake cycle of rats. Eur J Neurosci 12:726-730. CrossRef Medline

Rizvi TA, Murphy AZ, Ennis M, Behbehani MM, Shipley MT (1996) Medial preoptic area afferents to periaqueductal gray medullo-output neurons: a combined Fos and tract tracing study. J Neurosci 16:333-344. Medline

Sakai K, Koyama Y (1996) Are there cholinergic and non-cholinergic paradoxical sleep-on neurones in the pons? Neuroreport 7:2449-2453. CrossRef Medline

Sapin E, Lapray D, Bérod A, Goutagny R, Léger L, Ravassard P, Clément O, Hanriot L, Fort P, Luppi PH (2009) Localization of the brainstem GABAergic neurons controlling paradoxical (REM) sleep. PLoS One 4:e4272. CrossRef Medline

Sapin E, Bérod A, Léger L, Herman PA, Luppi PH, Peyron C (2010) A very large number of GABAergic neurons are activated in the tuberal hypothalamus during paradoxical (REM) sleep hypersomnia. PLoS One 5:e11766. CrossRef Medline

Sastre JP, Buda C, Kitahama K, Jouvet M (1996) Importance of the ventrolateral region of the periaqueductal gray and adjacent tegmentum in the 
control of paradoxical sleep as studied by muscimol microinjections in the cat. Neuroscience 74:415-426. CrossRef Medline

Sherin JE, Shiromani PJ, McCarley RW, Saper CB (1996) Activation of ventrolateral preoptic neurons during sleep. Science 271:216-219. CrossRef Medline

Sirieix C, Gervasoni D, Luppi PH, Léger L (2012) Role of the lateral paragigantocellular nucleus in the network of paradoxical (REM) sleep: an electrophysiological and anatomical study in the rat. PLoS One 7:e28724. CrossRef Medline

Swanson LW (1998) Brain maps: structure of the rat brain: a laboratory guide with printed and electronic templates for data, models, and schematics, Ed 2. New York: Elsevier.

Tsunematsu T, Kilduff TS, Boyden ES, Takahashi S, Tominaga M, Yamanaka A (2011) Acute optogenetic silencing of orexin/hypocretin neurons induces slow-wave sleep in mice. J Neurosci 31:10529-10539. CrossRef Medline

Uschakov A, Grivel J, Cvetkovic-Lopes V, Bayer L, Bernheim L, Jones BE, Mühlethaler M, Serafin M (2011) Sleep-deprivation regulates alpha-2 adrenergic responses of rat hypocretin/orexin neurons. PLoS One 6:e16672. CrossRef Medline

van den Pol AN, Acuna-Goycolea C, Clark KR, Ghosh PK (2004) Physiological properties of hypothalamic MCH neurons identified with selective expression of reporter gene after recombinant virus infection. Neuron 42:635-652. CrossRef Medline

Vanini G, Torterolo P, McGregor R, Chase MH, Morales FR (2007) GABAergic processes in the mesencephalic tegmentum modulate the occurrence of active (rapid eye movement) sleep in guinea pigs. Neuroscience 145:1157-1167. CrossRef Medline

Verret L, Goutagny R, Fort P, Cagnon L, Salvert D, Léger L, Boissard R, Salin P, Peyron C, Luppi PH (2003) A role of melanin-concentrating hormone producing neurons in the central regulation of paradoxical sleep. BMC Neurosci 4:19. CrossRef Medline

Verret L, Léger L, Fort P, Luppi PH (2005) Cholinergic and noncholinergic brainstem neurons expressing Fos after paradoxical (REM) sleep deprivation and recovery. Eur J Neurosci 21:2488-2504. CrossRef Medline

Verret L, Fort P, Gervasoni D, Léger L, Luppi PH (2006) Localization of the neurons active during paradoxical (REM) sleep and projecting to the locus coeruleus noradrenergic neurons in the rat. J Comp Neurol 495: 573-586. CrossRef Medline

Xi MC, Morales FR, Chase MH (1999) Evidence that wakefulness and REM sleep are controlled by a GABAergic pontine mechanism. J Neurophysiol 82:2015-2019. Medline

Yamuy J, Mancillas JR, Morales FR, Chase MH (1993) C-fos expression in the pons and medulla of the cat during carbachol-induced active sleep. J Neurosci 13:2703-2718. Medline 